\title{
Variability of winter haze over the Beijing- Tianjin-Hebei region tied to wind speed in the lower troposphere and particulate sources
}

\author{
Peijun $\underline{\text { Shi }}^{1,2,3^{*}}$, Gangfeng Zhang ${ }^{1,3}$, Feng Kong ${ }^{1,3}$, \\ Deliang $\underline{\text { Chen }}^{4}$, Cesar $\underline{\text { Azorin-Molina }}^{4}$, Jose A. $\underline{\text { Guijarro }}^{5}$ \\ Surnames (or family names) are underlined \\ ${ }^{1}$ State Key Laboratory of Earth Surface Processes and Resource Ecology, Beijing \\ Normal University, Beijing 100875, China; \\ ${ }^{2}$ Key Laboratory of Environmental Change and Natural Disaster of Ministry of \\ Education, Beijing Normal University, Beijing 100875, China; \\ ${ }^{3}$ Academy of Disaster Reduction and Emergency Management, Ministry of Civil \\ Affairs \& Ministry of Education, Beijing Normal University, Beijing 100875, China; \\ ${ }^{4}$ Regional Climate Group, Department of Earth Sciences, University of Gothenburg, \\ Gothenburg, 40530, Sweden \\ ${ }^{5}$ State Meteorological Agency, Delegation of the Balearic Islands, Palma de Mallorca, \\ Spain
}

Manuscript resubmitted to Atmospheric Research Research Article

Running head: Wind speed changes in the lower troposphere influence winter haze 12 July 2018

* Corresponding author address: PeiJun Shi, State Key Laboratory of Earth Surface Processes and Resource Ecology, Beijing Normal University, 19\#Xinjiekouwai Street, Haidian District, Beijing 100875, China.

E-mail: spj@bnu.edu.cn 
Abstract: This study analyzes the variability of winter haze days and visibility in the Beijing-Tianjin-Hebei $(\mathrm{BTH})$ region, in relation to the regional average wind speed changes in the lower troposphere and emissions for 1961-2014. Winter mean surface meteorological data, NCEP/NCAR atmospheric reanalysis data, and fossil fuel emission data are used. The results reveal a significant increase in the haze days of +0.8 days decade ${ }^{-1}(p<0.01)$, and a subsequent decline in visibility of $-1.56 \mathrm{~km}$ decade $^{-1}(p<0.01)$. Most interestingly, an accelerated increase in the number of haze days was observed for the last 11 -year period $\left(+8.3\right.$ days decade $\left.^{-1}, p<0.01\right)$ of the study period (2004-2014). Regression analysis indicates that the increase of haze occurrence and decrease in visibility are partly due to the significant $(p<0.01)$ declining trend of the mean wind speed in the lower troposphere $\left(-0.19 \mathrm{~m} \mathrm{~s}^{-1}\right.$ decade $^{-1}$ at $10 \mathrm{~m},\left(-0.23 \mathrm{~m} \mathrm{~s}^{-1}\right.$ decade $^{-1}$ at $\left.925 \mathrm{hPa}\right)$, and $-0.21 \mathrm{~m} \mathrm{~s}^{-1}$ decade $^{-1}$ at $\left.850 \mathrm{hPa}\right)$, and partly due to the declining (dust storm frequency as a proxy, -0.41 days $\operatorname{dec}^{-1}$ ) surrounding particulate sources and increasing fossil fuel emissions (total carbon emission as a proxy, +48206.8 thousand metric tons $\mathrm{dec}^{-1}$ ). Specifically, wind speed changes in the lower troposphere explain $41.3 \%$ of the interannual varation of the winter haze days and $71.2 \%$ of the visibility variance. These are extended to $51.7 \%$ and $81.6 \%$ respectively when combined with information about the natural (dust storm frequency) and anthropogenic (fossil fuel emissions) particulate sources. Therefore, the analyses show that wind speed changes in the lower troposphere, together with the varied natural and anthropogenic sources of particulates, play a key role in modulating winter haze and visibility conditions in the BTH area. 
Key words: winter haze days, visibility, wind speed changes, lower troposphere, dust storm frequency, fossil fuel emissions, Beijing-Tianjin-Hebei.

\section{Introduction}

With China's rapid urbanization (Bai et al., 2014) and industrialization in recent years, more pollutants have been released into the atmosphere and the occurrence of haze days in Eastern China have risen (Song et al., 2013; Ding and Liu, 2014). Because of this, serious pollution incidents in big cities have been occurring more frequently (Zhang et al., 2012), especially in the Beijing-Tianjin-Hebei (BTH) area (Zhang et al., 2016). These continuous haze pollution events consequently have negative effects on human health (Huang et al., 2014; Li et al., 2017) and transportation (Fu et al., 2014), becoming a major environmental issue.

Most previous haze studies have focused on the role played by anthropogenic emissions on physical and chemical compositions of haze pollution in China's biggest cities (Xu et al., 2013; Zhao et al., 2013). These studies found that high pollutant emissions and chemical reactions in the stable atmosphere have caused serious pollution events in China's big cities. Under global climate change (IPCC, 2013), however, the long-term trend of haze conditions in Eastern China is not solely related to strengthened anthropogenic activity, but also to variability in climate conditions (e.g., Lin et al., 2015).

Recently, attention has been given to the influence of large-scale atmospheric 
circulation changes, such as the East Asian winter monsoon, and other factors in the global climate system on haze conditions (Wu et al., 2016; Zhao et al., 2016). Xiao et al. (2015) found that interannual haze variability is closely related to Atlantic sea surface temperatures. Li et al. (2016) also observed that a weakened (strengthened) East Asian winter monsoon causes the increase (decrease) of haze. Meanwhile, Yin et al. (2015a) showed that increased haze conditions were associated with the weakening of the East Asian winter monsoon from 1961 to 2015. Further, Wang et al. (2015) found a significant negative correlation between haze days in Eastern China and Arctic sea ice change.

Previous studies have also shown that haze formation is closely related to emissions of air pollutants from human activities and modulated by atmospheric conditions ( $\mathrm{Li}$ et al., 2016). In addition, several studies have demonstrated that near-surface wind speed significantly affects air pollution concentrations (Liu et al., 2013; Zhang et al., 2014). Furthermore, Lin et al. (2015) found that average near surface wind speed above $3.5 \mathrm{~m} \mathrm{~s}^{-1}$ can significantly lessen concentrations of fine particulate matter (i.e., PM2.5). Therefore, wind has been suggested as a key atmospheric driver of haze because weak wind speed reduces the dilution and diffusion effects in the atmosphere (Yin et al., 2015b).

Many recent studies have reported a declining trend in near-surface wind speed (i.e., $\sim 10$-meter height) over mid-latitude continental surfaces in different regions across the world (McVicar et al., 2008; Pirazzoli and Tomasin, 2003; Brázdil et al., 2009; Wan et al., 2010; Azorin-Molina et al., 2014, 2016); see McVicar et al. (2012) 
for a comprehensive review on wind speed trends. Contrary to this negative trend, termed "stilling" by Roderick et al. (2007), positive trends have been reported over oceans (Wentz et al., 2007), coastal areas (Pinard, 2007), and high-latitude regions (i.e., $>70^{\circ}$; McVicar et al., 2012; Minola et al., 2016), thus introducing uncertainties into understandings of wind speed change. In China, studies have revealed that nearsurface wind speed has declined in most areas of the country (McVicar et al., 2012; Lin et al., 2013). Nevertheless, different descending rates have been found as wind speed has dropped significantly in Eastern China and along coastal regions, especially in the BTH region (Liu et al., 2009) and Yangtze River Delta (Shi et al., 2015), where the serious haze pollution has typically occurred.

Changes in surface wind speed play a major role in the variability of haze conditions ( $\mathrm{Li}$ et al., 2016), particularly in winter when less precipitation cause weakened wet deposition of haze particle. Deng et al. (2013) found that haze layers are $1-1.5 \mathrm{~km}$ thick and, therefore, changes in haze conditions were not only related to near-surface wind speed, but also to low-level winds in the boundary layer which impact its formation. However, there have been few studies that focus on the influence of long-term wind speed change in the lower troposphere on haze variability, especially under high emission scenarios; e.g., those produced by China's recent and rapid urbanization and industrialization (Zhang et al., 2016). Thus, quantification into the impacts of regional wind speed changes in the lower troposphere on haze conditions remains to be conducted. Particularly, it has been a challenge to characterize haze dynamics due to a lack of long-term observation data for 
tropospheric atmospheric haze particles. Nevertheless, studies have demonstrated that visibility can be used to retrieve the degree of haze in the absence of haze particle observation data in the troposphere, as well as degradation results from light scattering and absorption by atmospheric particles from natural or anthropogenic sources (Sabetghadam et al., 2012; Baddock et al., 2014).

Taken the above into consideration, the main objective of this study is to examine the variability of winter haze over the BTH region for 1961-2014 and its possible longterm relationship with wind speed in the lower troposphere regarding both natural and anthropogenic particulate sources. The BTH region is located in northern China, with approximately 110 million residents and $216000 \mathrm{~km}$ in size, and became one of most economically developed regions and the third economic engine in China. With the rapid urbanization and industrialization over the past 3 decades, and the increase of air pollution (Chan and Yao, 2008, Gao et al., 2011 and Zhang et al., 2018), a better understanding of the influence of low-level winds on haze and visibility is strongly needed. For instance, the continuous haze pollution in January 2013 greatly threatened human health and traffic safety (Sun et al., 2014).The analysis uses unique datasets of atmospheric visibility and haze days, derived from synoptic meteorological stations covering the $\mathrm{BTH}$ region where economic development is rapid and the haze problem represents a serious environmental issue for the population (Zhang et al., 2016). As such, this study helps better understand the effects of wind speed changes, as well as natural and human factors in the variability of winter haze and visibility conditions. 


\section{Data and methods}

144

145

146

147

\subsection{Data}

\subsubsection{Haze days}

Haze refers to the degradation of atmospheric visibility and obscurity caused by a large number of suspended fine particulate matter (i.e., $\mathrm{PM}_{2.5}$ and $\mathrm{PM}_{10}$ ) in the atmosphere (Wu et al., 2009) over a period of a few days to a month. Haze particulates mainly come from direct emissions such as coal fires, vehicle exhausts, and dust, as well as secondary reactions in the atmosphere (Huang et al., 2014). In atmospheric observation, haze is mainly determined by visibility and near-surface relative humidity(China Meteorological Administration, 2010). When the relative humidity of the atmosphere is less than $90 \%$, atmospheric turbidity is mainly caused by haze ( $\mathrm{Wu}$ et al., 2009).Thus judging criteria of haze days is : (i) horizontal visibility $\leqslant 10 \mathrm{~km}$ at $14: 00$ (Beijing local time) and (ii) relative humidity $\leqslant 90 \%$. Meanwhile, rain, hail, and other weather phenomena (i.e., snow) are excluded as constituting haze days. This was also applied by previous studies (e.g., Liu et al., 2013; Ding et al., 2014; Wu et al., 2016).

The China Meteorological Administration (CMA) executed tentative specifications of meteorological observations (ground part) from 1955 to 1979, and the observed visibility data were recorded in 9 levels of near-surface atmospheric visibility (Table 1). Thereafter, new specifications for surface meteorological observation were introduced. As such, the observed visibility data have been recorded in km since 1980 . 
As data for the entire period (i.e., 1961-2015) need to be processed consistently, the daily visibility observation data of all stations before 1980 were converted to $\mathrm{km}$ (Zhang et al., 2011); each level replaced by the median of corresponding distance. Meanwhile, the visibility data is inhomogeneous because the techniques used for the observations differ from before and after the 1980s; the quality and homogeneity of the visibility dataset are assessed in Section 2.2 below.

Winter refers to December, as well as the January and February of the following year, and the regional average number of haze days $(N \grave{H} D)$ of each winter in the BTH region is represented by:

$$
N \grave{H} D=\frac{1}{m} \sum_{i=1}^{m} M_{i}
$$

, where $\mathrm{m}$ is the number of stations (here $\mathrm{m}=23$ ) and $\mathrm{M}$ denotes the number of haze days in a station each winter. The regional average visibility (VİS) of each winter in the BTH region is represented by:

$$
V \grave{I} S=\frac{1}{m} \sum_{i=1}^{m}\left(\frac{1}{n} \sum_{j=1}^{n} V_{i j}\right)
$$

, where $m$ is the number of stations (here $m=23$ ), $n$ is the number of days in winter, and $\mathrm{V}$ denotes the daily visibility.

\subsubsection{Surface meteorological data}

Observed data from 23 synoptic meteorological stations in the BTH region were supplied by the CMA for 1961-2015. This dataset (anemometers currently used are displayed in brackets) contains daily average 10-meter wind speed (NSW, in $\mathrm{m} \mathrm{s}^{-1}$, measured by EN (electromagnetism) type automatic anemoscope), air temperature (in 
186

187

${ }^{\circ} \mathrm{C}$, measured by dry bulb thermometer), relative humidity (in \%, measured by dry and wet bulb thermometer), and visibility (in $\mathrm{km}$, measured by a scatter infrared visibility detector ) recorded at four time intervals (i.e., 02:00, 08:00, 14:00, and 20:00; Beijing local time) from January 1, 1961 to December 31, 2015. As Figure 1 displays, the distribution of the stations is relatively uniform, indicating that the average values of meteorological parameters offer good representations of the whole BTH region. The study area is located in northern China; a flat terrain area of $216,000 \mathrm{~km}^{2}$ with 110 million residents. Supplementary Table S1 provides a description of the meteorological station network used in this study.

\subsubsection{Reanalyzed data: NCEP/NCAR}

The NCEP/NCAR monthly atmospheric reanalysis data (https://www.esrl.noaa.gov/psd/data/gridded/data.ncep.reanalysis.pressure.html; last accessed April 1, 2018) (Kalnay et al., 1996) of an area bounded by $32.5^{\circ} \mathrm{N} \sim 45.0^{\circ} \mathrm{N}$ and $110.0^{\circ} \mathrm{E} \sim 122.5^{\circ} \mathrm{E}$ (i.e., covering the whole BTH region) were used for 1961-2015. The winter haze layer is generally located in the troposphere below 1-1.5 km (Deng et al., 2013). Thus, decadal haze variation was not only affected by near-surface wind speed, but also wind speed in the near-surface to the top of the lower troposphere which directly influenced the horizontal transportation and vertical diffusion of haze (Li et al., 2016). As such, the reanalyzed atmospheric parameters used were: u-wind and v-wind speeds at 925 and $850 \mathrm{hPa}$; geopotential heights of 925 and $850 \mathrm{hPa}$; and air temperature at $1000,925,850,700$, and $500 \mathrm{hPa}$. All reanalyzed datasets have the 
horizontal grid-spacing of $2.5^{\circ} \times 2.5^{\circ}$.

\subsubsection{Fossil fuel emission data as a proxy for human activity}

The total Fossil Fuel Emission (here after FFE, in thousand metric tons of carbon), which contain the emissions from fossil-fuel burning, emissions from cement manufacture, and emissions from gas flaring, represent most of the emission sources from human, was used as a proxy for human activity emission. The FFE of China (Boden et al., 2016) for 1961-2014 was provided by the Carbon Dioxide Information Analysis Center of Oak Ridge National Laboratory (http://cdiac.essdive.lbl.gov/ftp/Global_Carbon_Project/National_Carbon_Emissions_2016_v1.0.xlsx); _last accessed April 1, 2018). The proportion of Gross Domestic Product (GDP (billion yuan)) for the BTH region in China was used for retrieving the total FFE in this area. The GDP was provided by the National Bureau of Statistics of China for 1961-2014 (http://data.stats.gov.cn/index.htm; last accessed July 1, 2018).

\subsubsection{Dust storm frequency as a proxy for the natural source of particulates}

Frequent dust events led to the increase of mineral content (i.e., calcium ions; $\mathrm{ca}^{2+}$ ) in haze particulates (Zhang et al., 2018). Dust storm frequency was therefore used to indicate the natural mineral aerosol particle emissions (mainly dust). Dust storm information was supplied by the CMA for January 1, 1961 to December 31, 2015. Winter Dust Storm Frequency (hereafter DSF) is the total winter dust storm days divided by the number of stations that had recorded the dust storms in Northern China 
for the area bounded by $35^{\circ} \mathrm{N} \sim 45.0^{\circ} \mathrm{N}$ and $105.0^{\circ} \mathrm{E} \sim 120^{\circ} \mathrm{E}$, which is considered the main dust sources for the BTH region (Sun et al., 2006).

\subsection{Homogenization of daily meteorological data}

Station relocations, anemometer height changes (Wan et al., 2010) or even degradation of anemometers (Azorin-Molina et al., 2018) may cause breakpoints in the observed wind speed data. The same with new observation practices adopted for relative humidity, air temperature, and visibility data. Due to the lack of meta information about inhomogeneity, the homogenization method implemented in the R package CLIMATOL version 3.0 (http://www.climatol.eu/; last accessed April 1, 2018) was applied. This is because it uses the well-established relative Standard Normal Homogeneity Test (SNHT) (Alexandersson, 1986) to detect sudden break points, and has been successfully used in previous homogenization studies (AzorinMolina et al., 2014, 2017).

The test was applied on differences between every single observed series and the composite reference series computed from the nearest surrounding data in a normalized form. Normalizations were achieved by the normal ratio method (dividing observed series by the long-term averages of the series) in the case of visibility and wind speed, and standardization (removing averages and dividing observed series by the standard deviations) for air temperature and relative humidity. The SNHT was applied to the series of differences between the observed and reference series in two ways: (i) on stepped time windows to minimize the possible masking effects of multiple breaks, and (ii) on the whole series. At each stage, the series were 

271 initially calculated and defined as $\mathrm{W} 925=\sqrt{U_{925}^{2}+V_{925}^{2}}$. The vertical shear of wind 272 between $1000 \mathrm{hPa}$ and $925 \mathrm{hPa}$ (hereafter VSW) was defined as VSW= $273 \sqrt{\left(U_{850}-U_{1000}\right)^{2}+\left(V_{850}-V_{1000}\right)^{2}}$. The atmospheric stratification thermodynamic 274 instability is commonly indicated by A index (Zhang et al., 2014), which is derived by

successively split by the most significant break point in an iterative process until no SNHT value higher than a prescribed threshold remained. All missing data were filled in using the normalized reference data at the end of the process. Moreover, the older visibility observations were coded according to a fixed scale, but from the 1980s onward visibility measurements have been reported in $\mathrm{km}$. However, the numerous break points detected in the homogenization process appear more or less evenly distributed along the study period, without any evident accumulation in the 1980s (Figure 2). This is an expected result for relative homogenization methods when a change is applied (almost) simultaneously to the whole observation network. Besides, changing from a scale of fixed intervals to measured visibility can decrease the granularity of the data, but no relevant changes in the averages should be introduced. After completing this robust quality control and homogenization protocol, 23 homogeneous series were used in this study.

\section{Statistical analyses}

The average winter wind speed at $925 \mathrm{hPa}$ (hereafter W925) and average wind speed at $850 \mathrm{hPa}$ (hereafter W850) were calculated. Using the example of W925, the average value of $\mathrm{U} 925$ and $\mathrm{V} 925$ in the areas $32.5^{\circ} \mathrm{N}-45^{\circ} \mathrm{N}$ and $105^{\circ} \mathrm{E}-122.5^{\circ} \mathrm{E}$ were 
the following formulation: $A=\left(T_{850}-T_{500}\right)-\left[\left(T_{850}-T_{d 850}\right)+\left(T_{700}-T_{d 700}\right)+\left(T_{500}-T_{d 500}\right)\right) ; T$ and $T_{d}$ denote air temperature and dew point temperature respectively. The subscript denote 500,700 , and $850 \mathrm{hPa}$. The A index indicates the stratification instability in the lower and middle atmosphere. The winter condition of atmospheric stability in BTH is represented by vertical air temperature difference (in ${ }^{\circ} \mathrm{C}$ ) between 925 and $1000 \mathrm{hPa}$ (Zhang et al., 2014).

In order to quantitatively recognize the contributions of wind speed in the lower troposphere and emissions to haze day and visibility variations, variance based on multivariate regression (Zhang et al., 2016) was used. In the analysis, wind speed in the lower troposphere was denoted by the near-surface wind speed, W925, VSW, and W850, and emissions were denoted by the DSF and FFE. All these series were standardized in the actual calculation. A multiple linear regression (MLR) equation was established for a standardized sequence based on multiple regression theory (Pedroni et al., 1999).

The trend was calculated using the least-squares method (in $\mathrm{m} \mathrm{s}^{-1}$ decade $^{-1}$; hereafter $\mathrm{dec}^{-1}$ ), with 5-years moving average series on the basis of the original series, considering the disturbance of periodic vibration to the original series (Shi et al., 2014). Moreover, the Pearson correlation analysis and Student's t-test (with fixed plevels as $p<0.05$ or $p<0.01$ ) were used to determine the correlation significance of the data (Zhang et al., 2015), and a 15-year Gaussian low-pass filter was used to determine the decadal changes.

\section{Results}




\subsection{Trends of winter haze days and visibility}

The mean winter visibility and number of haze days in the BTH are presented in Figure 3 which shows that the haze days experienced three phases of change: (i) a gradual increase with a rate of +3.3 days $\operatorname{dec}^{-1}(p<0.01)$ from 1961 to 1989 ; (ii) a decline with a rate of -5.0 days $\operatorname{dec}^{-1}(p<0.01)$ from 1990 to 2003; and, (iii) another gradual increase with a rate of +8.3 days $\operatorname{dec}^{-1}(p<0.05)$ from 2004 to 2014 , but particularly in the last 5 years of the study period. For instance, the number of haze days in 2013 was abnormally high (27.7 days), reaching the top value of the mean series. The visibility also experienced three clear changing phases, but displayed an almost opposite trend behavior: (i) a gradual decrease at a rate of $-3.22 \mathrm{~km} \mathrm{dec}^{-1}$ $(p<0.01)$ from 1961 to 1989 ; (ii) a continuous increase at a rate of $+5.47 \mathrm{~km} \mathrm{dec}^{-1}$ $(p<0.05)$ from 1990 to 1995 ; and, (iii) a constant decrease at a rate of $-0.07 \mathrm{~km} \mathrm{dec}^{-1}$ (not significant at $p<0.05$ ) from 1996 to 2014. As a whole, the number of haze days displayed an overall increasing trend of +0.8 days $\operatorname{dec}^{-1}(p<0.01)$, with an average of 20.4 haze days for the entire 54 year period. Meanwhile, the visibility showed a declining trend of $-1.56 \mathrm{~km} \mathrm{dec}^{-1}(p<0.01)$ over the same period, with an average value of $13.2 \mathrm{~km}$. The interannual and interdecadal (11-year moving average) correlation coefficients between the number of haze days and visibility were -0.59 and -0.67 (significant at $p<0.01$ ) respectively. This demonstrates that the trend of haze days and visibility were closely linked to each other at the interannual and interdecadal scales. The spatial distribution of haze days (Figure 4a) and visibility trends (Figure 4b) in the BTH region for 1961-2014 were also displayed. It shows that 74\% (17 stations, 14 
stations significant at $\mathrm{p}<0,05)$ of the stations showed an increasing haze day trend; the stations with the highest magnitude of increasing trends were mostly located in big cities (i.e., Beijing station, Tianjin station) and areas surrounded by machinery factories and chemical plants (i.e., Tanggu station). Meanwhile, 26\% (6 stations, 5 stations significant at $\mathrm{p}<0.05$ ) of the stations which showed an increasing trend were found in coastal (i.e., Huanghuai station) and some suburban areas (i.e., Zhangbei station). Moreover, all the stations displayed a degrading visibility of varying magnitude, including urban areas (i.e., Beijing station) and industrial districts (i.e., Tangshan station).

\subsection{Relationship between near surface wind speed and haze}

\subsubsection{Near-surface wind speed in haze vs. non-haze days}

In order to identify typical atmospheric conditions associated with winter haze days and show how these conditions differ from non-haze days, Figure 5 displays the near surface wind speed of haze days and non-haze days at the regional level. A slowdown of both wind speed in haze days and non-haze days dominated before 2000. However, a recovery was detected in the last 15 years of the study period with wind speed below $2 \mathrm{~m} \mathrm{~s}^{-1}$ in haze days. Besides, wind speed in haze days on average is lower than in non-haze situations, although both show a declining trend. The decreasing trend for haze days $\left(-0.29 \mathrm{~m} \mathrm{~s}^{-1} \mathrm{dec}^{-1} ; p<0.01\right)$ is of a greater magnitude than non-haze days ($\left.0.18 \mathrm{~m} \mathrm{~s}^{-1} \mathrm{dec}^{-1} ; p<0.01\right)$. Further, wind speed differences between both types of days tended to increase. 


\subsubsection{Impacts of different near-surface wind speed groups on haze}

343 On the contrary to the trend in haze days, the regional average winter wind speed anomaly showed a declining trend at a rate of $-0.19 \mathrm{~m} \mathrm{~s}^{-1} \mathrm{dec}^{-1}(p<0.01)$ from 1961 to 2014 (Figure 6 (a)). Table 2 shows that the frequencies of the average winter wind speed in the intervals $0-2 \mathrm{~m} \mathrm{~s}^{-1}$ and $2-3 \mathrm{~m} \mathrm{~s}^{-1}$ significantly increased $(\mathrm{p}<0.01)$ for 1961-2014. On the contrary, the frequencies for wind speeds higher than $3 \mathrm{~m} \mathrm{~s}^{-1}$ 
winter haze days and visibility. The analysis above shows that increases (decreases) in frequencies of calm wind $\left(<3 \mathrm{~m} \mathrm{~s}^{-1}\right)$ and decreases (increases) in frequencies of greater average wind speeds $\left(>3 \mathrm{~m} \mathrm{~s}^{-1}\right)$ mean lower (higher) visibility and more (less) haze days.

\subsection{The relationship of wind speeds at $925 / 850 \mathrm{hPa}$ and haze days}

Low-level (i.e., $925 \mathrm{hPa}$ and $850 \mathrm{hPa}$ ) wind speed in the troposphere can transport haze particulates for a long distance. Thus, Figure 6(b) and (c) shows the evolution of winter mean wind speed anomalies for W925 and W850, denoting a decreasing trend of -0.23 and $-0.21 \mathrm{~m} \mathrm{~s}^{-1} \mathrm{dec}^{-1}$ for $1961-2014$ respectively. Both W925 and W850 weakened until 1970, strengthened during the 1970s, and declined significantly from 1981 to 2014. The correlation coefficients of W925 and W850 and haze days were $0.55(p<0.01)$ and $-0.51(p<0.05)$ respectively, and for visibility $0.56(p<0.01)$ and $0.47(p<0.01)$ respectively. This indicates that variations of W925 and W850 were closely related to the variability of haze days and visibility. The correlation coefficients of W925 and W850 and the near-surface wind speed were 0.42 and 0.41 $(p<0.01)$ respectively. This indicates that the variability of near-surface wind speed was consistent with the changes observed for W925 and W850. However, nearsurface wind speed and W925 showed higher correlations with haze days and visibility thanW850.

Winter wind speed in the BTH is dependent on the large scale pressure gradients between the Eurasian Continent and East Asia. Therefore, the regression coefficients 
of haze days to geopotential height at $925 \mathrm{hPa}$ and $850 \mathrm{hPa}$ were also calculated (see Figure7). The regression coefficients of geopotential height at $925 \mathrm{hPa}$ and $850 \mathrm{hPa}$ were found to be negative in the Eurasian Continent, including Siberia and Mongolia, and had an increasing negative scope with Isobaric gradient. Meanwhile, the geopotential height regression coefficients of East China to the northwest Pacific were positive. Similar anomalous patterns indicate that when more winter haze days appear across the BTH, negative anomalies of geopotential heights control a large area of the Eurasian Continent at $925 \mathrm{hPa}$ and $850 \mathrm{hPa}$. This means decreasing pressure gradients between the Eurasian Continent and East Asia, causing weak wind speeds at $925 \mathrm{hPa}$ and $850 \mathrm{hPa}$ which are obviously not conducive to the long distance transport of atmospheric haze particles. Moreover, the increasing negative scope from $850 \mathrm{hPa}$ to $925 \mathrm{hPa}$ demonstrates much weaker wind at $925 \mathrm{hPa}$, which is more closely linked to the formation of haze.

\subsection{The relationship between wind vertical shear and haze}

The regional average VSW in winter is displayed in Figure 8. This can represent atmospheric baroclinic instability, and is closely related to the genesis of synoptic disturbances. Besides, the vertical diffusion is also closely related to the VSW. The VSW shows a declining trend of $-0,07 \mathrm{~m} \mathrm{~s}^{-1} \mathrm{dec}^{-1}$ for $1961-2014$ and a weak negative relation between VSW and haze days $(-0.19$, not significant at $\mathrm{p}<0.05)$. Meanwhile, a stronger positive relation with visibility $(0.27, \mathrm{p}<0.05)$ was found.

We have demonstrated that variations of the regional winter haze days were closely 
related to the variability of wind speed for the whole lower troposphere; the weaker (stronger) the wind speed in the lower troposphere, the more (less) haze days were recorded. A regression analysis shows that wind speed in the lower troposphere explains $41.3 \%$ of haze days and $71.2 \%$ of visibility variances. However, a positive trend $\left(+0.4\right.$ day decade $\left.{ }^{-1}, \mathrm{p}<0.01\right)$ in haze residuals and a negative trend $(-0.91 \mathrm{~km}$ decade $\left.^{-1}, \mathrm{p}<0.01\right)$ in visibility residuals were detected. This means that the long-term variability of haze days and visibility must be explained by other factors. Changes in natural and fossil fuel emissions are suggested to be key factors.

\subsection{Additional role of the natural and anthropogenic particulate sources}

Fossil fuel emissions should also play a role in the haze days and visibility by discharging haze particles directly into the atmosphere. Figure 9 displays a significant decrease in DSF $\left(-0.41\right.$ days $\left.\operatorname{dec}^{-1}, p<0.01\right)$, and an increase in FFE $(+48206.8$ thousand metric tons $\operatorname{dec}^{-1}, p<0.01$ ) for 1961-2014. DSF had an opposite trend with haze days. However, the increased fossil fuel emissions were consistent with increased haze days except during the 1990s. Therefore, the MLR model between the wind speed in the lower troposphere (near surface wind speed W925 and W850, VSW) and emissions was added as explanatory variables to estimate haze days and visibility (Formulas 7 and 8).

$$
\begin{aligned}
& \mathrm{HD}=-5.45 \mathrm{NSW}-5.03 \mathrm{~W} 925-1.66 \mathrm{~W} 850+2.48 \mathrm{VSW}+2.11 \mathrm{DSF}+1.96 \mathrm{FFE}+1.06 \\
& \mathrm{VIS}=5.55 \mathrm{NSW}+1.70 \mathrm{~W} 925+1.77 \mathrm{~W} 850-0.05 \mathrm{VSW}-0.28 \mathrm{DSF}-1.2 \mathrm{FFE}+21.83
\end{aligned}
$$

The results show that the fitted curves follow the observed curves closely (Figure 
10). Correlation coefficients between the observed and fitted curves of haze days and visibility were $0.77(p<0.01)$ and $0.91(p<0.01)$ respectively. Moreover, there was no significant trend in haze and visibility residuals, which indicates the robustness of the regression functions. Wind speed in the lower troposphere, dust storm frequency, and fossil fuel emissions together can explain $51.7 \%$ of haze day and $81.6 \%$ of visibility variances. This is a significant increase compared to using the wind alone as shown in Section 4.4.

\section{Discussion}

The trend in winter haze days revealed a statistically significant $(\mathrm{p}<0.01)$ decline of +0.8 days decade ${ }^{-1}(\mathrm{p}<0.01)$ across the BTH region for $1961-2014$, with a clear dominance $(76 \%)$ of stations showing negative trends. This finding is in accordance with the overall increase of haze days in China (Ding et al., 2014, Wu et al., 2016). Most interestingly, a recent amplification of haze days was detected for the last 11 years of the study period (2004-2014). This can reflect the occurrence of serious haze events in the BTH; e.g., the persistent severe haze in Beijing, January 2013, which lasted more than 20 days (Zhang et al., 2014, Cai et al., 2017). Meanwhile, a subsequent decline in visibility of $-1.56 \mathrm{~km} \mathrm{decade}^{-1}(\mathrm{p}<0.01)$ was also found in the BTH for the same period, with negative trends in all stations. This in turn confirmed the increasing occurrence of haze because haze days always have lower visibility ( $\mathrm{Wu}$ et al., 2009). 
The near surface wind speed in haze days was weaker and decreased more quickly compared to non-haze days, indicating adverse wind dispersion conditions in haze days. The findings also confirmed that the average wind speed in the region was negatively correlated with haze days and positively correlated with visibility. These findings are similar to those of Li et al. (2016) and Wu et al. (2016). However, this study posits that different intervals of wind speed have different impacts on haze days and visibility. It was found that the opposite influence of wind speed frequency on haze days and visibility for wind speeds below $3 \mathrm{~m} \mathrm{~s}^{-1}$ (positive) and greater than $3 \mathrm{~m}$ $\mathrm{s}^{-1}$ (negative). Lin et al (2015) suggested that wind speed at $3.5 \mathrm{~m} \mathrm{~s}^{-1}$ may be a key threshold for $\mathrm{PM}_{2.5}$ concentration in China, thus wind speed at $3 \mathrm{~m} \mathrm{~s}^{-1}$ may play a similar role for haze days and visibility for our study region. This was also indicated by the weaker wind speed ( below $3 \mathrm{~m} \mathrm{~s}^{-1}$ ) at the near surface, which resulted in more haze days as wind speed is the key driving force of local ventilation. Further, the negative relationship between W850/W925 and the number of haze days also indicates that weakened wind speed in lower troposphere was conductive to the increase of haze days. Yet, this was due to a different mechanism than wind near surface because wind in lower troposphere mainly transports pollutants over a long distance. These results are in accordance with the influence of atmospheric circulation on haze - i.e., the East Asian winter monsoon (Li et al., 2016; Wu et al., 2016), Pacific Decadal Oscillation (Zhao et al., 2016), and the Eurasian pattern (Zhang et al., 2016 ) - as W950 and W850 were related to the change of large scale circulation. This is also evident from the anomalous pattern of regression coefficients of 
472

473

geopotential height at $925 \mathrm{hPa}$ and $850 \mathrm{hPa}$ with haze days, which were negative in the Eurasian Continent and positive in East China to the northwest Pacific.

In fact, besides the weakened horizontal wind in the lower troposphere, the decreased VSW indicated that synoptic-scale disturbances and vertical diffusion also weakened. Moreover, a sharp drop of atmospheric vertical thermodynamic instability (see Supplementary Figure S1) also enhances this effect. This means that the vertical mixing in the lower troposphere is not favorable for the transport of pollutants, resulting in increased haze days. Besides, the winter stability increased significantly $\left(+0.05^{\circ} \mathrm{C}\right.$ dec-1) for $1961-2014$ (see Supplementary Figure S2), making the mixing more difficult. More stable conditions tend to keep air pollutants such as smog close to surface. This mechanism might partly explains the long-term variability of haze and visibility across the BTH in winter. Indeed, positive correlations with haze days (r $=0.22$, not significant at $\mathrm{p}<0.05$ ) and statistically significant negative ones with visibility $(\mathrm{r}=-0.49, \mathrm{p}<0.05)$ were found. In addition to the role played by the strengthening of the atmospheric stability, the impact of other local drivers such as sea- and land-breeze circulations (Miao et al., 2017), urban heat islands (Chen et al., 2018) and topography (Bei et al., 2018) on episodic pollutants and air quality have also been analyzed. However, field experimental campaigns and simulations analyzing these factors have only been carried out for few study cases; therefore, a long-term study on the impact of all these drivers (i.e., not solely surface wind speed) on the changes of haze days and visibility deserve further future analysis 

speed in the lower troposphere, as well as by natural and anthropogenic emissions from 1961 to 2014. However, their roles may have changed with time due to the competing effects of these factors on haze (Zhao et al., 2013; Wu et al., 2016). This is evident in the clear decadal variability of winter haze days detected in the three welldefined phases described before. Meanwhile, wind speed and natural as well as anthropogenic sources also changed under different phases (see supplementary Table S2). The surface wind speed displayed the opposite trend compared to haze days among the three phases; that is significantly declined in the first and last phases, while increased in the second phase. W850, W925 and VSW only significantly decreased in the first phase and increased in the last two phases. DSF also displayed different trend in the three phases, significantly decreased in the first phase and increased in the last phase, whereas no trend was found in the second one. Lastly, significant increases were found for the FFE in all phases, with enlarged magnitude of trends.

In this paper, we only analyzed the physical process of winter haze, that is, the emissions. This is also confirmed by the high proportion of mineral aerosol in air- 
during the last 11 years of the study period caused sharply increasing fossil fuel emissions (e.g., nitrate and sulfate). This resulted in most atmospheric haze particles being composed of sulfate particles (Wang et al., 2006; Wu et al., 2009; Huang, et al., 2014; Zou et al., 2018 ), and the contribution of sand-dust aerosol particles to haze significantly decreased (Yang et al., 2018). For this period, however, haze formation not only related to physical processes but also to the chemical reaction of haze particulates (e.g., nitrate and sulfate) which also played a key role ( Huang et al., 2014), Thus, haze days dramatically increased for 2004-2014, especially from 2009 to 2014 .

Under high fossil fuel emissions and global warming (IPCC, 2013), the decline of wind speed in China has been partly attributed to the weakened pressure-gradient force in the lower troposphere (Guo et al., 2011; Chen et al., 2013), especially by a decrease in the air temperature gradient. To this end, most of the haze particles come from fossil fuel emissions (Wu et al., 2009; Huang, et al., 2014). From supplementary Figure S3 (a), it can be seen that increased air temperature in haze days is much higher than in non-haze days, with weak wind. That is, when the near-surface air temperature is high, the atmosphere is more stable (Wu et al., 2016) with liquidity variation not conducive to the diffusion of haze particles. On the other hand, the higher air temperature in haze days also caused higher relative humidity (see supplementary Figure S3 (b)), making these days more prone to the accumulation and hygroscopic growth of sulfate particles (Yu et al., 2018), especially from 1990 onward (see shifted fossil fuel emissions in Figure 10and high moving correlation 
coefficients between winter haze days and relative humidity in supplementary Figure S4). This, therefore, can strengthen light scattering and absorption by haze particles, consequently causing visibility degradation and haze intensification. Therefore, our results nevertheless suggest that the global effort in reducing fossil fuel emissions will contribute to decreasing the risk of haze events in the BTH.

\section{Conclusion}

The main conclusions of this study are as follows:

1. Number of winter haze days in the study region showed a distinct increasing trend whereas visibility showed a distinct declining trend for 1961-2014. Moreover, the increasing trend of haze days accelerated over the last 11 years of the study period (2004-2014).

2. While it is confirmed that wind speed in the lower troposphere is the key factor driving the interannual variability of winter haze days and visibility, natural and fossil fuel emissions of haze-inducing substances were found to be important for the increasing trend of haze days.

3. Wind speed in the lower troposphere and particulate sources together can explain $51.7 \%$ of the interannual variability of haze days and $81.6 \%$ of visibility. This makes wind speed and particulate sources two of the most critical factors for winter haze conditions in the study region.

\section{Acknowledgements}


This study was supported by the National Natural Science Foundation of China (Grant No.41621061), the National Key Research and Development Program-Global Change and Mitigation Project (Grant No.2016YFA0602404), funding from STINT (CH20156226), and the European Union's Horizon 2020 research and innovation program under the Marie Skłodowska-Curie grant agreement No. 703733 (STILLING project). The authors wish to acknowledge the anonymous reviewers for their detailed and helpful comments to the original manuscript

\section{Supporting information}

Table S1 Description of meteorological stations in the BTH

Table S2 Trends of surface wind speed (in $\mathrm{m} \mathrm{s}^{-1} \mathrm{dec}^{-1}$ ), W925 (in $\mathrm{m} \mathrm{s}^{-1} \mathrm{dec}^{-1}$ ), W850 (in $\mathrm{m} \mathrm{s}^{-1} \mathrm{dec}^{-1}$ ), VSW (in $\mathrm{m} \mathrm{s}^{-1} \operatorname{dec}^{-1}$ ) and DSF(in days $\operatorname{dec}^{-1}$ ) and FFE(in thousand metric tons dec-1) for different phases

Figure S1 Anomaly series of Atmospheric Thermodynamic Instability ( ATI) for 1961-2014 in the BTH: ATI=(T850-T500)-[( T850-Td850)+( T700-Td700)+( T500$\mathrm{Td} 500)$ ); $\mathrm{T}$ and $\mathrm{Td}$ denote temperature and dew point temperature respectively. The subscript denote 500,700 , and $850 \mathrm{hPa}$. The greater the ATI, the more unstable the stratification.

Figure S2 Variation of winter inversion in the BTH for 1961-2014. A 15-year lowpass Gaussian filter is drawn.

Figure S3. Winter near-surface characteristics of haze and non-haze days for (a) air temperature, and (b) relative humidity in the BTH for 1961-2014. 
581

582

583

584

585

586

587

588

589

590

591

592

593

594

595

596

597

598

599

600

601

602

Figure S4. 20-year moving correlation coefficients between winter haze days and relative humidity in the BTH for 1961-2014.

\section{References}

Alexandersson, H. 1986. A homogeneity test to precipitation data, Int. J. Climatol. 6(6):661-675, doi:10.1002/joc.3370060607.

Azorin-Molina, C., Vicente-Serrano, S.M., Mcvicar, T.R., Jerez, S., Sanchez-Lorenzo, A., López-Moreno, J.I., Revuelto, J., Trigo, R.M., Lopez-Bustins, J.A., EspíritoSanto, F., 2014. Homogenization and assessment of observed near-surface wind speed trends over Spain and Portugal, 1961-2011. J. Clim. 27, 3692-3712. https://doi.org/10.1175/JCLI-D-13-00652.1.

Azorin-Molina, C., Guijarro, J.A., McVicar, T.R., Vicente-Serrano, S.M., Chen, D., Jerez, S., Espírito-Santo, F., 2016. Trends of daily peak wind gusts in Spain and Portugal, 1961-2014. J. Geophys. Res. 121, 1059-1078. https://doi.org/10.1002/2015JD024485.

Azorin-Molina, C., Menendez, M., McVicar, T.R., Acevedo, A., Vicente-Serrano, S.M., Cuevas, E., Minola, L., Chen, D., 2017. Wind speed variability over the Canary Islands, 1948-2014: focusing on trend differences at the land-ocean interface and below-above the trade-wind inversion layer. Clim. Dyn. 0, 1-21. https://doi.org/10.1007/s00382-017-3861-0.

Azorin-Molina, C., Asin, J., McVicar, T.R., Minola, L., Lopez-Moreno, J.I., VicenteSerrano, S.M., Chen, D., 2018. Evaluating anemometer drift: A statistical 
approach to correct biases in wind speed measurement. Atmos. Res. 203, 175-188. https://doi.org/10.1016/j.atmosres.2017.12.010

Baddock, M.C., Strong, C.L., Leys, J.F., Heidenreich, S.K., Tews, E.K., McTainsh, G.H., 2014. A visibility and total suspended dust relationship. Atmos. Environ. 89, 329-336. https://doi.org/10.1016/j.atmosenv.2014.02.038.

Bai, X., Shi, P., Liu, Y., 2014. Realizing China's urban dream. Nature 509(7499):, 
626

627

628

629

630

631

632

633

634

635

636

637

638

639

640

641

642

643

644

645

646

Ding, Y., Liu, Y., 2014. Analysis of long-term variations of fog and haze in China in recent 50 years and their relations with atmospheric humidity. Sci. China Earth Sci. 57(1), 36-46.

Cai, W., Li, K., Liao, H., Wang, H., Wu, L., 2017. Weather conditions conducive to Beijing severe haze more frequent under climate change. Nat. Clim. Chang. 7(4), 257-262. https://doi.org/10.1038/nclimate3249.

Chen, L., Zhang, M., Zhu, J., Wang, Y., Skorokhod, A., 2018. Modeling Impacts of Urbanization and Urban Heat Island Mitigation on Boundary Layer Meteorology and Air Quality in Beijing Under Different Weather Conditions. Journal of Geophysical Research: Atmospheres

123, 4323-4344. https://doi.org/10.1002/2017JD027501

China Meteorological Administration. 2010. The State Standard of the People's Republic of China. Observation and forecasting levels of haze. QX/T 113-2010. China Meteorological Press, Beijing.Deng, T., Wu, D., Deng, X., Tan, H., Li, F., Chen, H., 2013. The vertical distribution of aerosol optical properties in a severe haze event. China Environ. Sci. 33(11),1921-1928(in Chinese).

Fu, G., Xu, W., Yang, R., Li, J., Zhao, C., 2014. The distribution and trends of fog and haze in the North China Plain over the past 30 years. Atmos. Chem. Phys. 14(21), 11949-11958. https://doi.org/10.5194/acp-14-11949-2014.

Gao, Y., Liu, X., Zhao, C., Zhang, M., 2011. Emission controls versus meteorological conditions in determining aerosol concentrations in Beijing during the 2008 

https://doi.org/10.5194/acp-11-12437-2011.

Guo, H., Xu, M., Hu, Q., 2011. Changes in near-surface wind speed in China: 19692005. Int. J. Climatol. 31(3), 349-358. https://doi.org/10.1002/joc.2091.

651

652

653

654

655

656

657

658

659

660

661

662

663

664

665

666

667

668

Huang, R.J., Zhang, Y., Bozzetti, C., Ho, K.F., Cao, J.J., Han, Y., Daellenbach, K.R., Slowik, J.G., Platt, S.M., Canonaco, F., Zotter, P., Wolf, R., Pieber, S.M., Bruns, E.A., Crippa, M., Ciarelli, G., Piazzalunga, A., Schwikowski, M., Abbaszade, G., Schnelle-Kreis, J., Zimmermann, R., An, Z., Szidat, S., Baltensperger, U., El Haddad, I., Prévôt, A.S.H., 2015. High secondary aerosol contribution to particulate pollution during haze events in China. Nature 514(7521), 218-222. https://doi.org/10.1038/nature13774.

Jiang, Y., Luo, Y., Zhao, Z., Tao, S., 2010. Changes in wind speed over China during 1956-2004. Theor. Appl. Climatol. 99, 421-430. https://doi.org/10.1007/s00704009-0152-7.

Kalnay, E., Kanamitsu, M., Kistler, R., Collins, W., Deaven, D., Gandin, L., Zhu, Y., 1996. The NCEP/NCAR 40-year reanalysis project. Bull. Am. Meteorol. Soc. $77(3)$ 437-471. https://doi.org/10.1175/15200477(1996)077<0437:TNYRP>2.0.CO;2.

Kang, D., Wang, H., 2005. Analysis on the decadal scale variation of the dust storm in North China. Sci. China Ser. D-Earth Sci. 48(12), 2260-2266. https://doi.org/10.1360/03yd0255.

Kurosaki, Y., Mikami, M., 2007.Threshold wind speed for dust emission in east Asia 
669

670

671

672

673

674

675

676

677

678

679

680

681

682

683

684

685

686

687

688

689

690

and its seasonal variations. J Geophys Res - Atmos. 112(D17),107-114. https://doi.org/10.1029/2006JD007988.

Li, Q., Zhang, R., Wang, Y., 2016. Interannual variation of the wintertime fog-haze days across central and eastern China and its relation with East Asian winter monsoon. Int. J. Climatol. 36(1), 346-354, https://doi.org/10.1002/joc.4350.

Li, H., Wu, H., Wang, Q., Yang, M., Li, F., Sun, Y., Qian, X., Wang, J., Wang, C., 2017. Chemical partitioning of fine particle-bound metals on haze-fog and nonhaze-fog days in Nanjing, China and its contribution to human health risks. Atmos. Res. 183, 142-150. https://doi.org/10.1016/j.atmosres.2016.07.016

Lin, C., Yang, K., Qin, J., Fu, R., 2013. Observed coherent trends of surface and upper-air wind speed over china since 1960. J Clim. 26(9), 2891-2903. https://doi.org/ 10.1175/JCLI-D-12-00093.1.

Lin, C., Yang, K., Huang, J., Tang, W., Qin, J., Niu, X., Chen, Y., Chen, D., Lu, N., Fu, R., 2015. Impacts of wind stilling on solar radiation variability in China. Sci. Rep. 5(5), 1-7. https://doi.org/10.1038/srep15135.

Liu, X., Li, J., Qu, Y., Han, T., Hou, L., Gu, J., Chen, C., Yang, Y., Liu, X., Yang, T., Zhang, Y., Tian, H., Hu, M., 2013. Formation and evolution mechanism of regional haze: A case study in the megacity Beijing, China. Atmos. Chem. Phys. 13, 4501-4514. https://doi.org/10.5194/acp-13-4501-2013.

McVicar, T.R., Van Niel, T.G., Li, L.T., Roderick, M.L., Rayner, D.P., Ricciardulli, L., Donohue, R.J., 2008. Wind speed climatology and trends for Australia, 19752006: Capturing the stilling phenomenon and comparison with near-surface 
691

692

693

694

695

696

697

698

699

700

701

702

703

704

705

706

707

708

709

710

711

712

reanalysis output. Geophys. Res. Lett. 35(20), 1-6. https://doi.org/10.1029/2008GL035627.

McVicar, T.R., Roderick, M.L., 2010. Atmospheric science: Winds of change. Nat. Geosci. 3(11), 747-748. https://doi.org/10.1038/ngeo1002.

McVicar, T.R., Roderick, M.L., Donohue, R.J., Li, L.T., Van Niel, T.G., Thomas, A., Grieser, J., Jhajharia, D., Himri, Y., Mahowald, N.M., Mescherskaya, A. V., Kruger, A.C., Rehman, S., Dinpashoh, Y., 2012. Global review and synthesis of trends in observed terrestrial near-surface wind speeds: Implications for evaporation.

J. Hydrol.

416-417,

$182-205$. https://doi.org/10.1016/j.jhydrol.2011.10.024.

Miao, Y., Guo, J., Liu, S., Liu, H., Zhang, G., Yan, Y., He, J., 2017. Relay transport of aerosols to Beijing-Tianjin-Hebei region by multi-scale atmospheric circulations. Atmospheric Environment 165, 35-45. https://doi.org/10.1016/j.atmosenv.2017.06.032

Minola, L., Azorin-Molina, C., Chen, D., 2016. Homogenization and assessment of observed near-surface wind speed trends across Sweden, 1956-2013. J Clim. 29(20), 7397-7415, https://doi.org/10.1175/JCLI-D-15-0636.1.

Pedroni, P., 1999. Critical Values for Cointegration Tests in Heterogeneous Panels with Multiple Regressors. Oxford B Econ Stat. 61(S1): 653-670.

Pirazzoli, P.A., Tomasin, A., 2003. Recent near-surface wind changes in the central Mediterranean and Adriatic areas. Int. J. Climatol. 23(8), 963-973, https://doi.org/ $10.1002 /$ joc. 925 
713

714

715

716

717

718

719

720

721

722

723

724

725

726

727

728

729

730

731

732

733

734

Pinard, J.P., 2007. Wind climate of the Whitehorse area. Artic. 60(3): 227-237.

Sabetghadam, S., Farhang, A,G., and Golestani, Y., 2012. Visibility trends in Tehran during 1958-2008. Atmos. Environ. 62, 512-520, https://doi.org/ 10.1016/j.atmosenv.2012.09.008.

Roderick, M.L., Rotstayn, L.D., Farquhar, G.D., Hobbins, M.T., 2007. On the attribution of changing pan evaporation. Geophys Res Lett. 34(17),251-270, https://doi.org/ 10.1029/ 2007GL031166.

Zhao, S., Li, J., Sun, C., 2016. Decadal variability in the occurrence of wintertime haze in central eastern China tied to the Pacific Decadal Oscillation. Sci. Rep. 6, 1-9. https://doi.org/10.1038/srep27424.

Shi, P., Sun, S., Wang, M., Li, N., Wang, J., Jin, Y., Gu, X., Yin, W., 2014. Climate change regionalization in China (1961-2010). Sci. China Earth Sci. 57, 26762689. https://doi.org/10.1007/s11430-014-4889-1.

Shi, P., Zhang, G., Kong, F., Ye, Q., 2015. Wind speed change regionalization in China (1961-2012). Adv. Clim. Chang. Res. 6, 151-158. https://doi.org/10.1016/j.accre.2015.09.006.

Song, L., Gao, R., Li, Y., Wang, G., 2014. Analysis of China's Haze days in the Winter Half year and the Climatic Background during 1961-2012. Adv. Climate Change R. 5(1),1-6.

Sun, Y., Zhuang, G., Wang, Y., Han, L., Guo, J., Dan, M., Zhang, W., Wang, Z., Hao, Z., 2004. The air-borne particulate pollution in Beijing - Concentration, composition, distribution and sources. Atmos. Environ. 38, 5991-6004. 
Sun, Y., Jiang, Q., Wang, Z., Fu, P., Li, J., Yang, T., Yin, Y., 2014. Investigation of the sources and evolution processes of severe haze pollution in Beijing in January 2013. Journal of Geophysical Research 119, 4380-4398. https://doi.org/10.1002/2014JD021641.

IPCC. 2013. Climate Change 2013: The Physical Science Basis. Contribution of Working Group I to the Fifth Assessment Report of the Intergovernmental Panel on Climate Change. Cambridge: Cambridge University Press.

Vautard, R., Cattiaux, J., Yiou, P., Thépaut, J.N., Ciais, P., 2010. Northern Hemisphere atmospheric stilling partly attributed to an increase in surface roughness. Nat. Geosci. 3(11), 756-761. https://doi.org/10.1038/ngeo979.

Wan, H., Wang, X.L., Swail, V.R., 2010. Homogenization and trend analysis of Canadian near-surface wind speeds. J. Clim. 23(5), 1209-1225. https://doi.org/10.1175/2009JCLI3200.1.

Wang, Y., Zhuang, G., Sun, Y., An, Z., 2006. The variation of characteristics and formation mechanisms of aerosols in dust, haze, and clear days in Beijing. Atmos. Environ. 40, 6579-6591. https://doi.org/10.1016/j.atmosenv.2006.05.066.

Wang, H., He, S., 2012.Weakening relationship between East Asian winter monsoon and ENSO after mid-1970s. Chin. Sci. Bull. 57, 3535-3540.

Wang, H., Chen, H, and Liu, J., 2015.Arctic Sea Ice Decline Intensified Haze Pollution in Eastern China. Atmos. Oceanic Sci. Lett. 8,1-9. https://doi.org/10.3878/AOSL20140081. 
Wang, R., Liu, B., Li, H., Zou, X., Wang, J., Liu, W., Cheng, H., Kang, L., Zhang, C., 2017. Variation of strong dust storm events in Northern China during 1978-2007. Atmos. Res. 183, 166-172. https://doi.org/10.1016/j.atmosres.2016.09.002.

Wang, Z., Ding, Y., He, J., Yu, J., 2004. An updating analysis of the climate change in China in recent 50 years. Acta Meteorol. Sin. 62(2),228-236(in Chinese).

Wentz, F.J., Ricciardulli, L., Hilburn, K., Mears, C., 2007. How much more rain will global warming bring? $\quad$ Science. 317(5835), 233-235, https://doi.org/10.1126/science.1140746.

Wu, D., Wu, X., Zhu, X., 2009. The fog and haze. Beijing: China Meteorological Press.198 (in Chinese).

Wu, P., Ding, Y., Liu, Y., Li, X., 2016. Influence of the East Asia winter monsoon and atmospheric humidity on the wintertime haze frequency over central-eastern China. Acta Meteorol. Sin. 74(3), 352-66(in Chinese).

Xu, W., Chen, H., Li, D., Zhao, F., Yang, Y., 2013. A case study of aerosol characteristics during a haze episode over Bei-jing, Procedia, Environ. Sci. 18,404-411(in Chinese)

Xiao, D., Li, Y., Fan, S., Zhang R, Sun, J., Wang, Y., 2015.Plausible influence of Atlantic Ocean SST anomalies on winter haze in China. Theor.Appl. Climatol. 122(1), 249-257. https://doi.org/10.1007/s00704-014-1297-6.

Yang, Y., Russell, L.M., Lou, S., Liao, H., Guo, J., Liu, Y., Singh, B., Ghan, S.J., 2017. Dust-wind interactions can intensify aerosol pollution over eastern China. Nat. Commun. 8, 1-8. https://doi.org/10.1038/ncomms15333. 
779

780

781

782

783

784

785

786

787

788

789

790

791

792

793

794

795

796

797

798

799

800

Yang, Y., Wang, H., Smith, S.J., Zhang, R., Lou, S., Qian, Y., Ma, P.L., Rasch, P.J., 2018. Recent intensification of winter haze in China linked to foreign emissions and meteorology. Sci. Rep. 8, 1-10. https://doi.org/10.1038/s41598-018-20437-7.

Yin, Z., Wang, H., Yuan, D., 2015a. Interdecadal increase of haze in winter over North China and the Huang-huai Area and the weakening of the East Asia Winter Monsoon. Chin. Sci. Bull. 60(15), 1395-1400(in Chinese).

Yin, Z, Wang, H., Guo, W., 2015b. Climatic change features of fog and haze in winter over North China and Huang-Huai Area. Sci. China Earth Sci. 58(8): 1370-1376. https://doi.org/10.1007/s11430-015-5089-3.

Yu, F., Wang, Q., Yan, Q., Jiang, N., Wei, J., Wei, Z., Yin, S., 2018. Particle size distribution, chemical composition and meteorological factor analysis: A case study during wintertime snow cover in Zhengzhou, China. Atmos. Res. 202, 140147. https://doi.org/10.1016/j.atmosres.2017.11.016

Zhang, K., Ma, Y., Xin, J., Liu, Z., Ma, Y., Gao, D., Wu, J., Zhang, W., Wang, Y., Shen, P., 2018. The aerosol optical properties and PM2.5components over the world's largest industrial zone in Tangshan, North China. Atmos. Res. 201, 226234. https://doi.org/10.1016/j.atmosres.2017.10.025

Zhang, L., Wu, J., Zhang, W., 2011. Analysis of visibility variations in China from 1955 to 2000. J. Lanzhou U. 47(6), 46-55(in Chinese).

Zhang, Q., He, K., Huo, H., 2012. Policy: cleaning China's air. Nature. 484(7393), 161-162, https://doi.org/10.1038/484161a.

Zhang, R., Li, Q., Zhang, R., 2014. Meteorological conditions for the persistent severe 
801

802

803

804

805

806

807

808

809

810

811

812

813

814

fog and haze event over eastern China in January 2013. Sci. China Earth Sci. 57(1), 26-35.

Zhang, Z., Zhang, X., Gong, D., Kim, S.J., Mao, R., Zhao, X., 2016. Possible influence of atmospheric circulations on winter haze pollution in the BeijingTianjin-Hebei region, northern China. Atmos. Chem. Phys. 16(2), 561-571. https://doi.org/10.5194/acp-16-561-2016.

Zhao, X., Zhao, P, Xu, J., Meng, W., Pu, W., Dong, F., He, D., Shi, Q., 2013. Analysis of a winter regional haze event and its formation mechanism in the North China Plain. Atmos. Chem. Phys. 13(11), 5685-5696. https://doi.org/10.5194/acp13-5685-2013.

Zhong, J., Zhang, X., Wang, Y., Liu, C., Dong, Y., 2018. Heavy aerosol pollution episodes in winter Beijing enhanced by radiative cooling effects of aerosols. Atmospheric Research 209, 59-64. https://doi.org/10.1016/j.atmosres.2018.03.011. Zou, J., Liu, Z., Hu, B., Huang, X., Wen, T., Ji, D., Liu, J., Yang, Y., Yao, Q., Wang, Y., 2018. Aerosol chemical compositions in the North China Plain and the impact on the visibility in Beijing and Tianjin. Atmos. Res. 201, 235-246. https://doi.org/10.1016/j.atmosres.2017.09.014

\section{Table captions}

Table 1. Correspondence of near-surface atmosphere visibility and horizontal distance Table 2 Trend in the frequency of daily wind speed and its relation to visibility and haze days for 1961-2014. 
825 Table 1. Correspondence of near-surface atmosphere visibility and horizontal distance

826

\begin{tabular}{cc}
\hline Level of near-surface & Visibility distance $\mathbf{L}(\mathbf{k m})$ \\
atmosphere visibility & $\mathrm{L}<0.05$ \\
\hline Level 0 & $0.05 \leqslant \mathrm{~L}<0.2$ \\
\hline Level 1 & $0.2 \leqslant \mathrm{~L}<0.5$ \\
\hline Level 2 & $0.05 \leqslant \mathrm{~L}<1.0$ \\
\hline Level 3 & $1.0 \leqslant \mathrm{~L}<2.0$ \\
\hline Level 4 & $2.0 \leqslant \mathrm{~L}<4.0$ \\
\hline Level 5 & $4.0 \leqslant \mathrm{~L}<10.0$ \\
\hline Level 6 & $10.0 \leqslant \mathrm{~L}<20.0$ \\
\hline Level 7 & $20.0 \leqslant \mathrm{~L}<50.0$ \\
\hline Level 8 & $50 \leqslant \mathrm{~L}$ \\
\hline Level 9 & \\
\hline
\end{tabular}

827

828

829

830 Table 2 Trend in the frequency of daily wind speed and its relation to visibility and 831 haze days for 1961-2014.

\begin{tabular}{lccc}
\hline Average wind & Trend & Correlation & Correlation \\
speed $\left(\mathrm{m} \mathrm{s}^{-1}\right)$ & $\left(\right.$ days $\left.\mathrm{dec}^{-1}\right)$ & with visibility & with haze days \\
\hline
\end{tabular}




\begin{tabular}{cccc}
\hline $0-2$ & $3.0^{* *}$ & $-0.72^{* *}$ & $0.53^{* *}$ \\
\hline $2-3$ & $1.1^{* *}$ & $-0.46^{* *}$ & 0.01 \\
\hline $3-4$ & $-0.7^{* *}$ & $0.63^{* *}$ & $-0.57^{* *}$ \\
\hline $4-5$ & $-0.9^{* *}$ & $0.79^{* *}$ & $-0.50^{* *}$ \\
\hline $5-6$ & $-0.8^{* *}$ & $0.83^{* *}$ & $-0.42^{* *}$ \\
\hline $6-7$ & $-0.6^{* *}$ & $0.89^{* *}$ & $-0.50^{* *}$ \\
\hline $7-8$ & & & $-0.45^{* *}$ \\
\hline $8-9$ & $-0.4^{* *}$ & $0.88^{* *}$ & $-0.41^{* *}$ \\
\hline $9-10$ & $-0.3^{* *}$ & $0.84^{* *}$ & $-0.37^{* *}$ \\
\hline$>10$ & $-0.2^{* *}$ & $0.78^{* *}$ & $-0.42^{* *}$ \\
\hline & & & \\
\hline & $-0.2^{* *}$ & $0.81^{* *}$ & \\
\hline
\end{tabular}

833

834 


\section{Figure captions}

Figure 1. Terrain map of the BTH and location (for numbers see Table S1) of the 23 meteorological stations used in this study.

Figure 2. Number of splits per year for visibility over the BTH region for 1961-2014

Figure 3. Mean winter haze days and visibility in the BTH region for 1961-2014. A 15 -year low-pass Gaussian filter is drawn.

Figure 4. Distribution of (a) winter haze days and (b) visibility trend in the BTH for 1961-2014.

Figure 5. Regional mean winter near-surface wind speed of haze days and non-haze days in the BTH for 1961-2014. A 15-year low-pass Gaussian filter is drawn.

Figure 6. Regional mean winter mean wind speed anomalies over the BTH at (a) near surface, (b) $925 \mathrm{hPa}$ and (c) $850 \mathrm{hPa}$ for 1961-2014. A 15-year low-pass Gaussian filter is drawn. (The correlation coefficient (r) between wind speed and haze days is shown for each plot. Anomalies are drawn with respect to the 1981-2010 mean.)

Figure 7. Distribution of the regression coefficients of (a) H925 and (d) H850 upon the regional mean haze days (H925 and H850 denote the geopotential height at 925 and $850 \mathrm{hPa}$ ); dots indicate regressions that are significant at the $95 \%$ confidence level.

Figure 8. Regional mean vertical shear of winter wind speed between $1000 \mathrm{hPa}$ and $850 \mathrm{hPa}$ for $1961-2014 . \mathrm{R}$ is the correlation coefficient between the vertical shear of the wind speed and number of haze days.

Figure 9. Temporal evolution of the regional mean winter haze day trend and dust 
storm frequency $\left(*_{-}\right)$(a) as well as the regional mean fossil fuel emission (b) in the BTH for 1961-2014.

Figure 10. The observed and fitted winter (a) average haze days and (b) visibility in the BTH for 1961-2014.

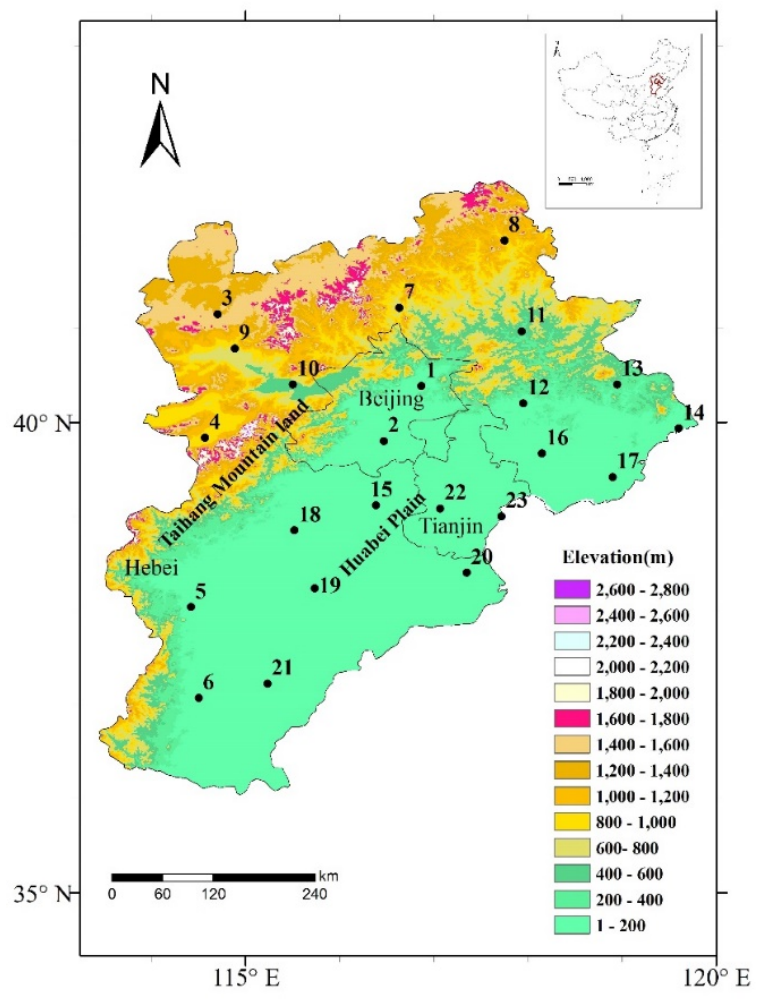

Figure 1. Terrain map of the BTH and location (for numbers see Table S1) of the 23 meteorological stations used in this study. 


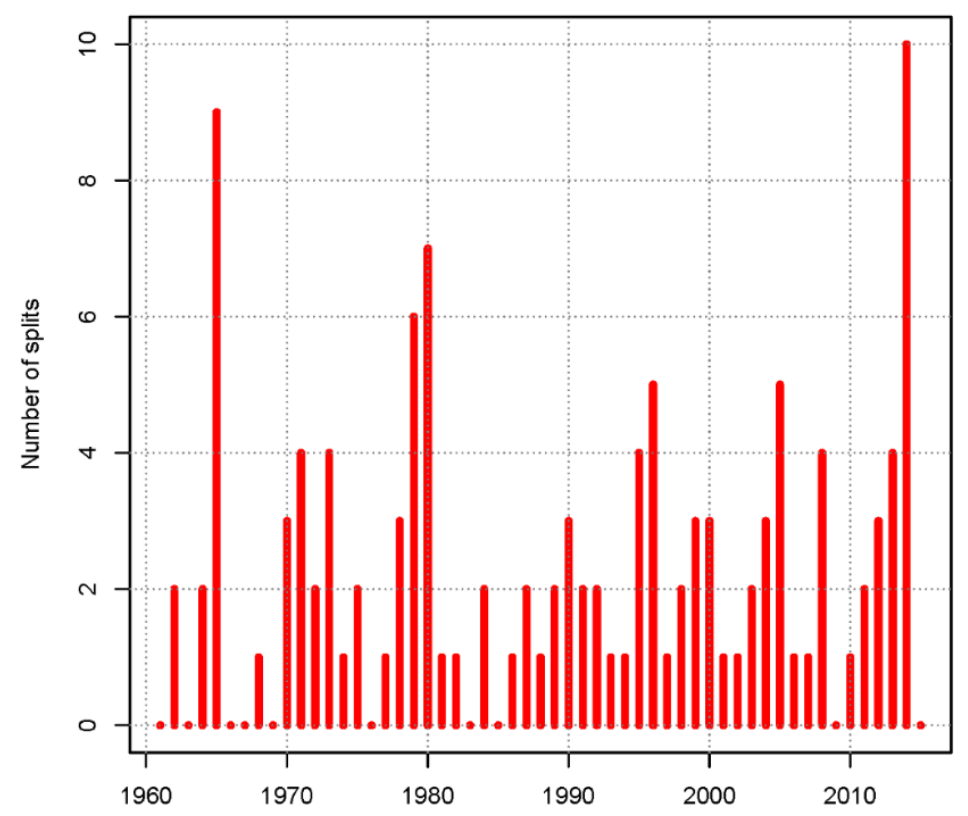

Figure 2. Number of splits per year for visibility over the BTH region for 1961-2014

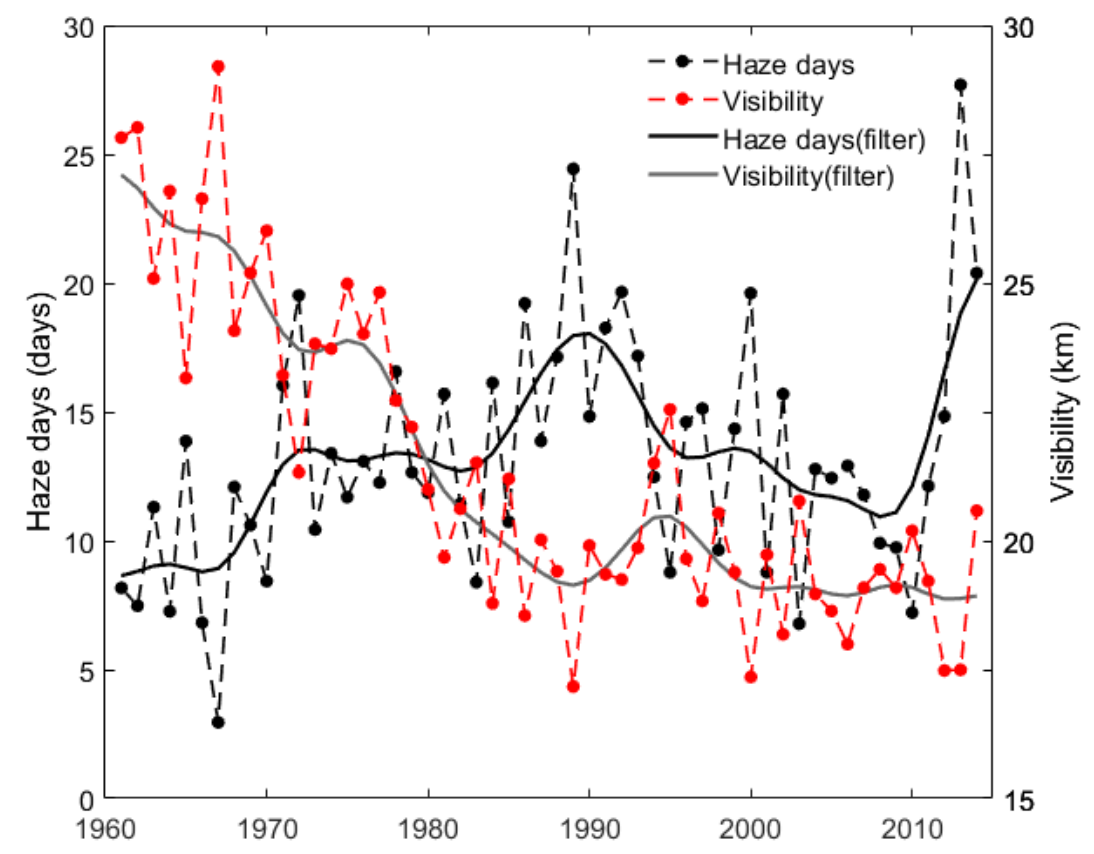

Figure 3. Mean winter haze days and visibility in the BTH region for 1961-2014. A 15-year low-pass Gaussian filter is drawn. 

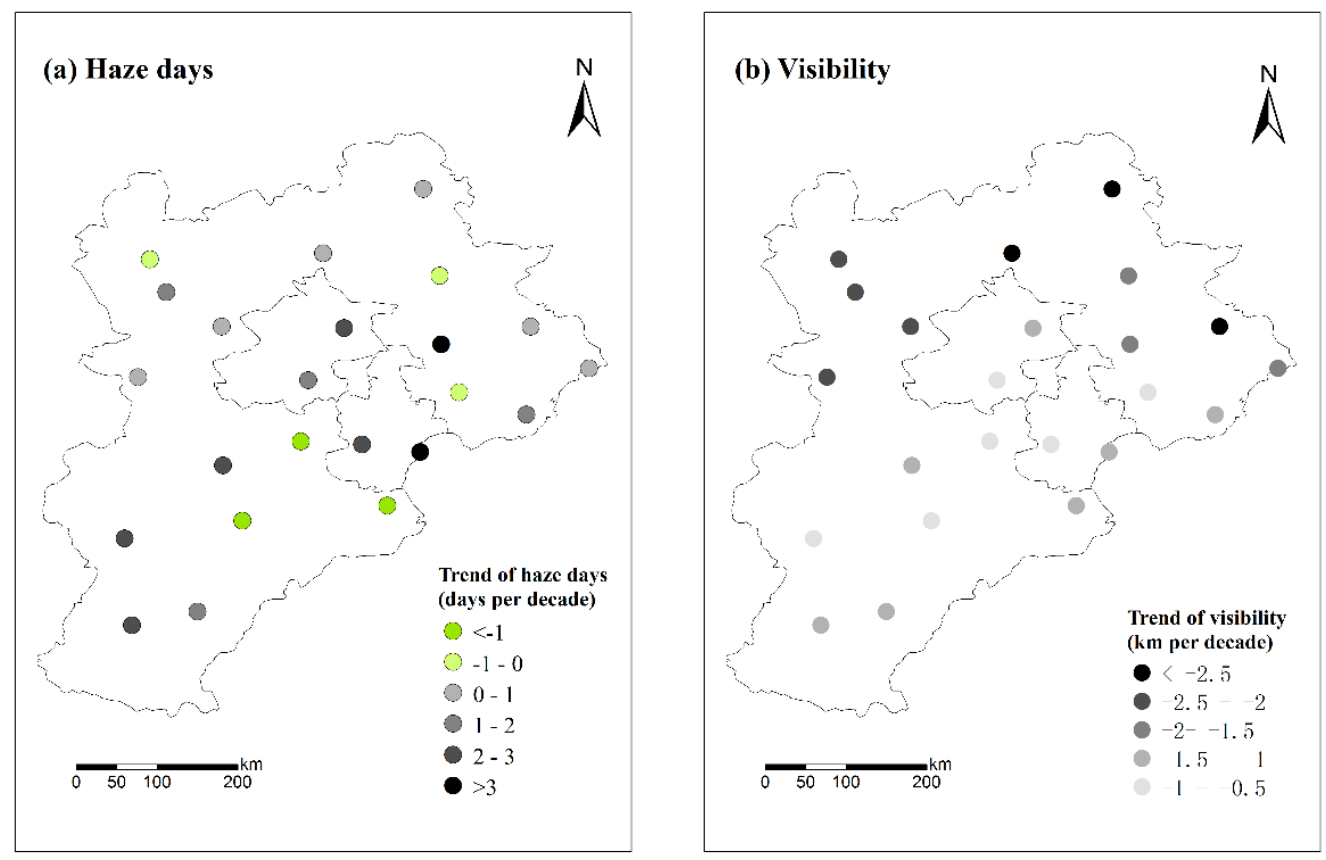

Figure 4. Distribution of (a) winter haze days and (b) visibility trend in the BTH for 1961-2014.

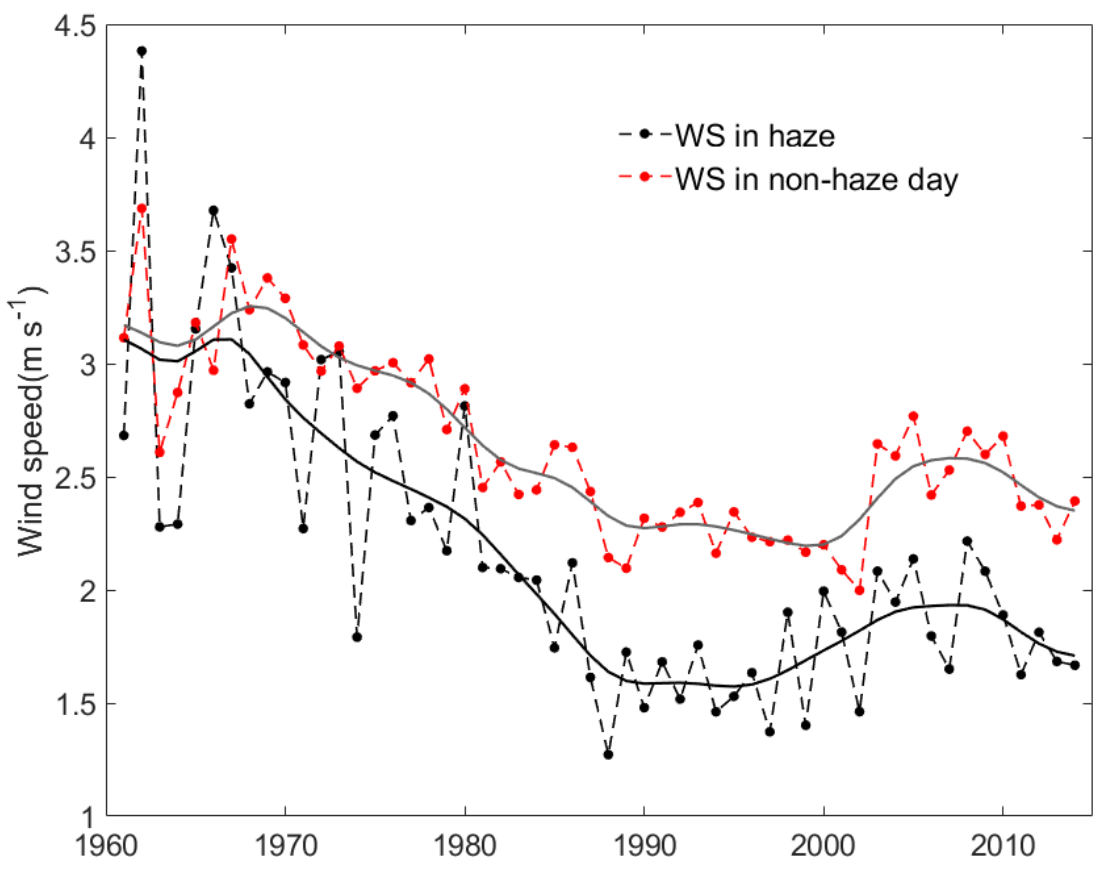

Figure 5. Regional mean winter near-surface wind speed of haze days and non-haze days in the BTH for 1961-2014. A 15-year low-pass Gaussian filter is drawn. 

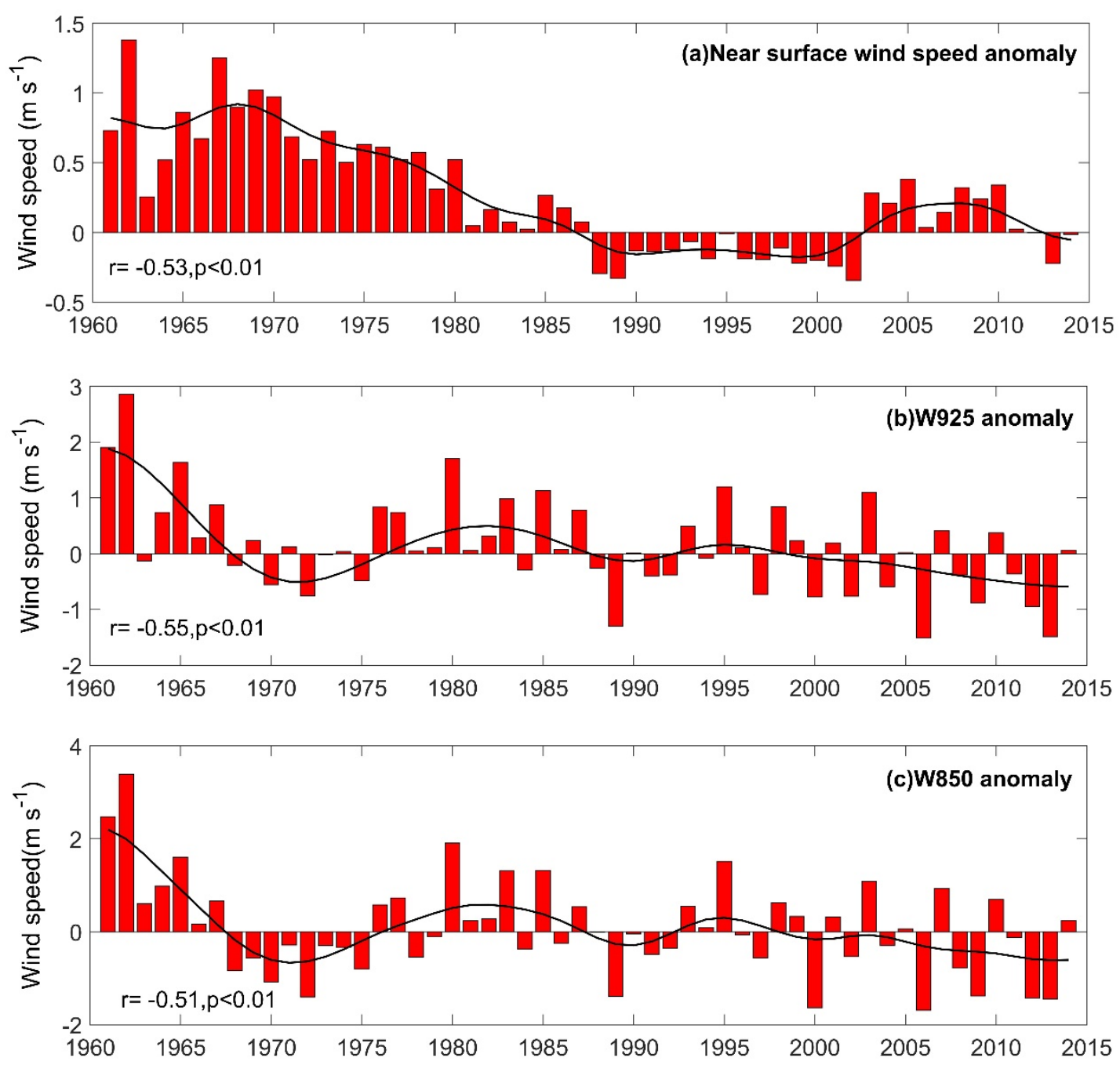

Figure 6. Regional mean winter mean wind speed anomalies over the BTH at (a) near surface, (b) $925 \mathrm{hPa}$ and (c) $850 \mathrm{hPa}$ for 1961-2014. A 15-year low-pass Gaussian filter is drawn. (The correlation coefficient (r) between wind speed and haze days is shown for each plot. Anomalies are drawn with respect to the 1981-2010 mean.) 

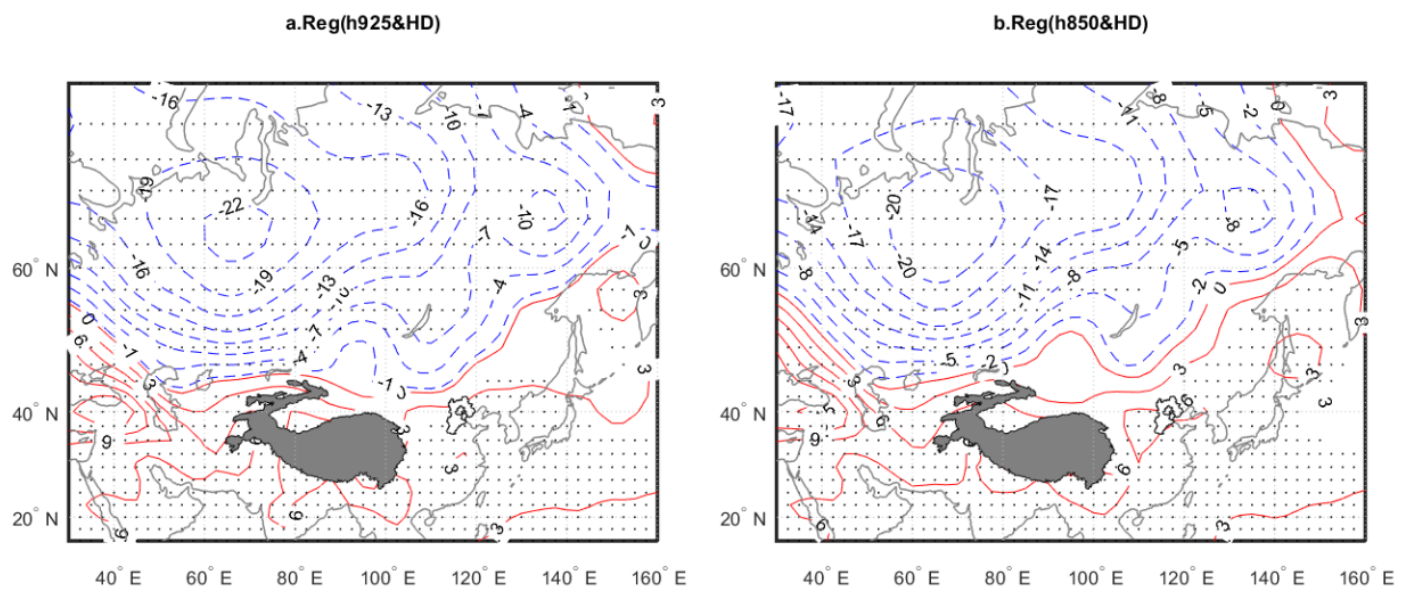

Figure 7. Distribution of the regression coefficients of (a) H925 and (d) H850 upon the regional mean haze days (H925 and H850 denote the geopotential height at 925 and $850 \mathrm{hPa}$ ); dots indicate regressions that are significant at the $95 \%$ confidence level.

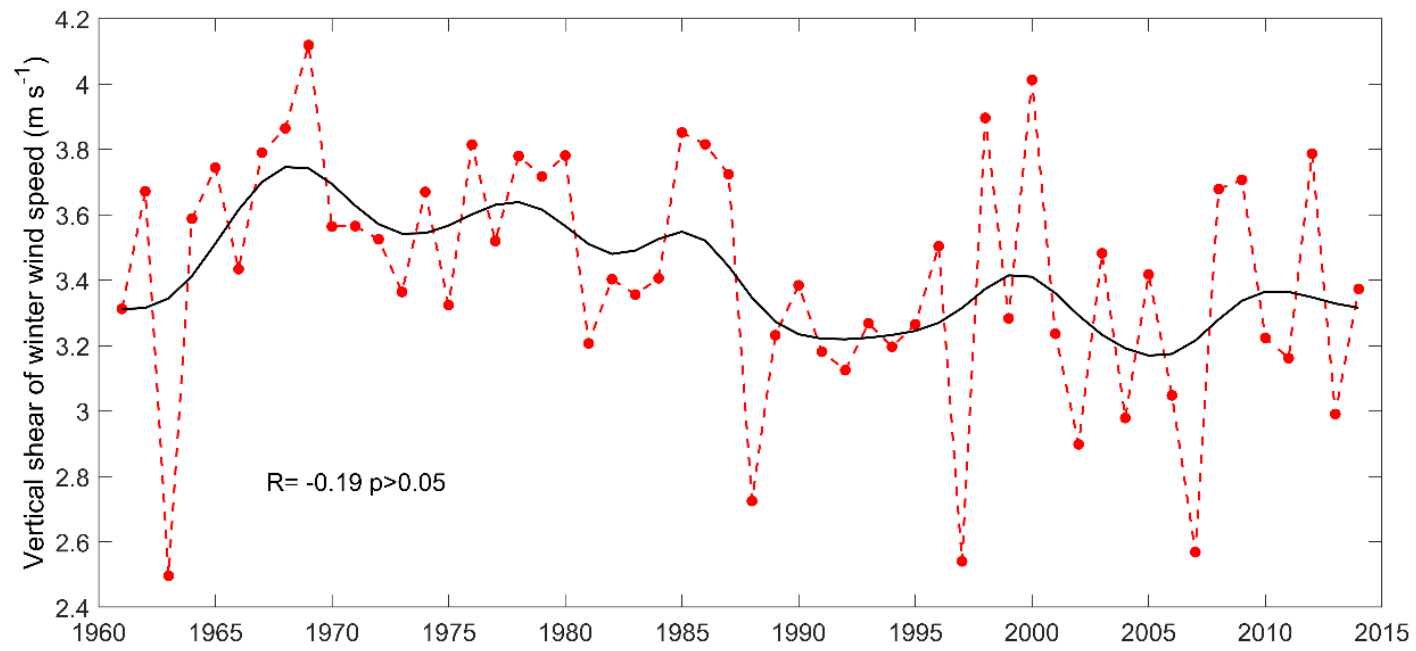

Figure 8. Regional mean vertical shear of winter wind speed between $1000 \mathrm{hPa}$ and $850 \mathrm{hPa}$ for 1961 - 2014. $\mathrm{R}$ is the correlation coefficient between the vertical shear of the wind speed and haze days. 

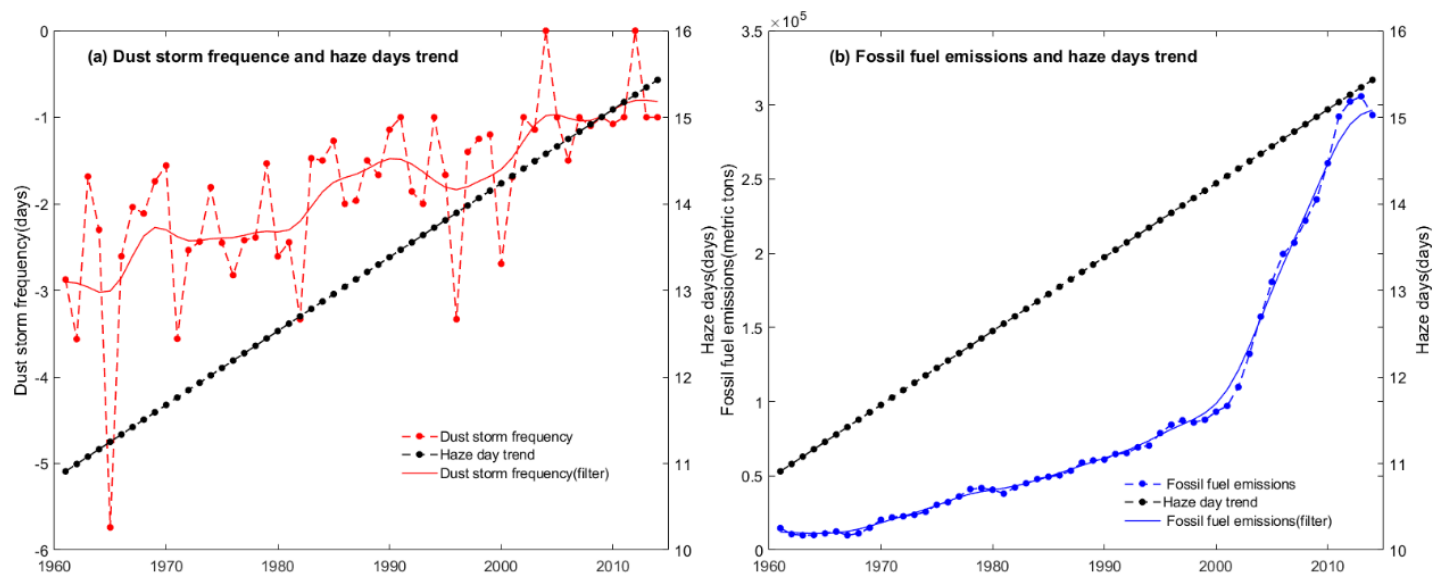

Figure 9. Temporal evolution of the regional mean winter haze day trend and dust storm frequency $\left(*_{-}\right)$(a) as well as the regional mean fossil fuel emission (b) in the BTH for 1961-2014.

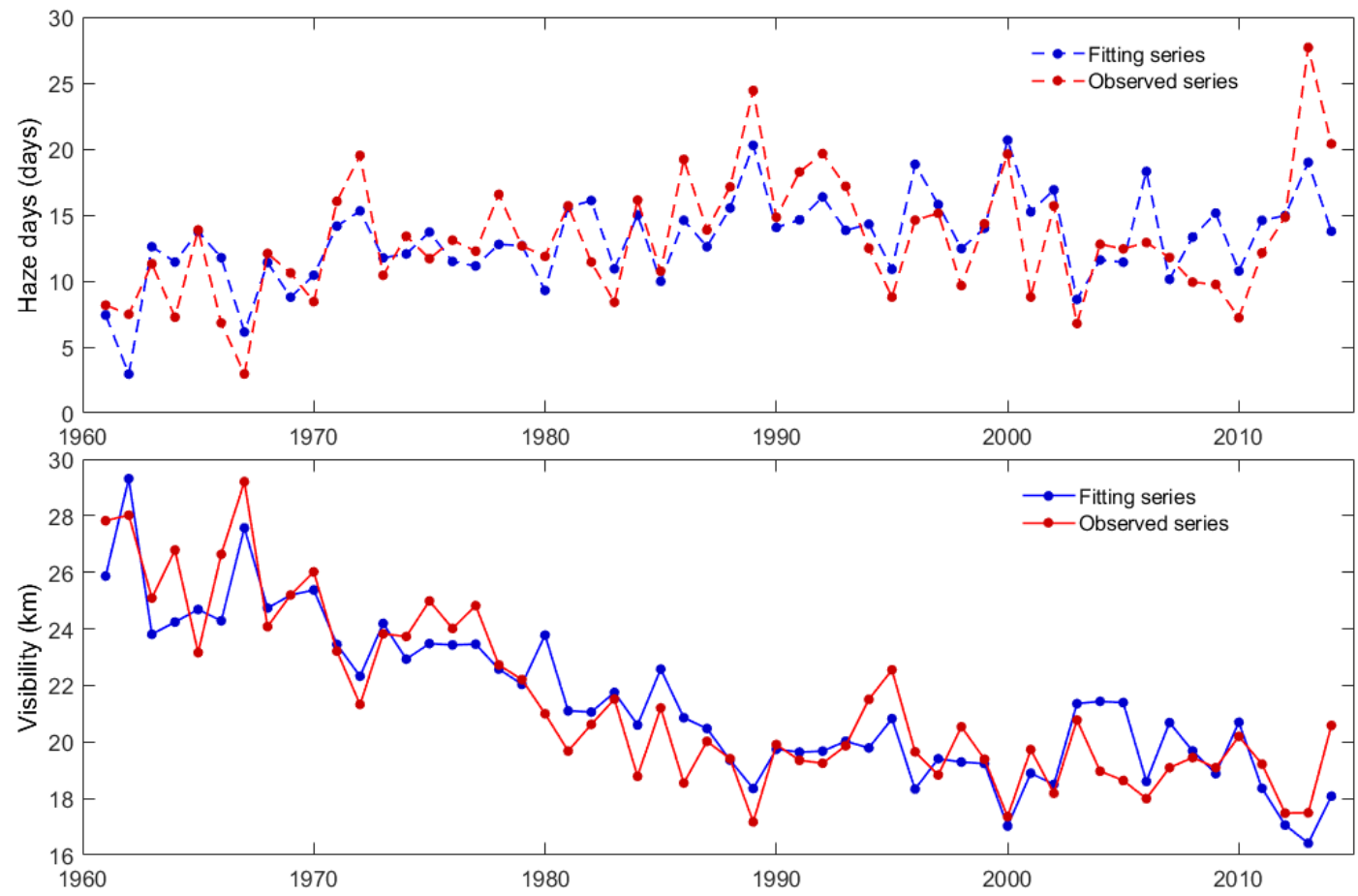

Figure 10. The observed and fitted winter (a) average haze days and (b) visibility in the BTH for 1961-2014. 


\title{
Variability of winter haze over the Beijing- Tianjin-Hebei region tied to wind speed in the lower troposphere and particulate sources
}

\author{
Peijun $\underline{\text { Shi }}^{1,2,3^{*}}$, Gangfeng Zhang ${ }^{1,3}$, Feng Kong ${ }^{1,3}$, \\ Deliang $\underline{\text { Chen }}^{4}$, Cesar $\underline{\text { Azorin-Molina }}^{4}$, Jose $\underline{\text { A Guijarro }}^{5}$
}

Surnames (or family names) are underlined

${ }^{1}$ State Key Laboratory of Earth Surface Processes and Resource Ecology, Beijing Normal University, Beijing 100875, China;

${ }^{2}$ Key Laboratory of Environmental Change and Natural Disaster of Ministry of Education, Beijing Normal University, Beijing 100875, China;

${ }^{3}$ Academy of Disaster Reduction and Emergency Management, Ministry of Civil Affairs \& Ministry of Education, Beijing Normal University, Beijing 100875, China;

${ }^{4}$ Regional Climate Group, Department of Earth Sciences, University of Gothenburg, Gothenburg, 40530, Sweden

${ }^{5}$ State Meteorological Agency, Delegation of the Balearic Islands, Palma de Mallorca, Spain

* Corresponding author address: PeiJun Shi, State Key Laboratory of Earth Surface Processes and Resource Ecology, Beijing Normal University, Beijing 100875, China;

E-mail: spj@bnu.edu.cn 


\section{Supplementary Tables}

Table S1 Description of meteorological stations in the BTH.

Table S2 Trends of surface wind speed (in $\mathrm{m} \mathrm{s}^{-1} \mathrm{dec}^{-1}$ ), W925 (in $\mathrm{m} \mathrm{s}^{-1} \mathrm{dec}^{-1}$ ), W850 (in $\mathrm{m} \mathrm{s}^{-1} \mathrm{dec}^{-1}$ ), VSW (in $\mathrm{m} \mathrm{s}^{-1} \mathrm{dec}^{-1}$ ) and DSF (in days dec ${ }^{-1}$ ) and FFE (in thousand metric tons $\mathrm{dec}^{-1}$ ) for different phases

Table S1 Description of meteorological stations in the BTH

\begin{tabular}{clccccc}
\hline Number & Station & $\begin{array}{c}\text { Latitude } \\
\left({ }^{\circ} \mathrm{N}\right)\end{array}$ & $\begin{array}{c}\text { Longitude } \\
\left({ }^{\circ} \mathrm{E}\right)\end{array}$ & $\begin{array}{c}\text { Elevation } \\
(\mathrm{m})\end{array}$ & Area & $\begin{array}{c}\text { Location of } \\
\text { stations }\end{array}$ \\
\hline 1 & Miyun & 40.38 & 116.87 & 73 & Beijing & Plain \\
2 & Beijing & 39.80 & 116.47 & 32 & Beijing & Plain \\
3 & Zhangbei & 41.15 & 114.70 & 1394 & Hebei & Mountain \\
4 & Weixian & 39.83 & 114.57 & 910 & Hebei & Mountain \\
5 & Shijiazhuang & 38.03 & 114.42 & 81 & Hebei & Plain \\
6 & Xingtai & 37.07 & 114.50 & 78 & Hebei & Plain \\
7 & Fengning & 41.22 & 116.63 & 661 & Hebei & Mountain \\
8 & Weichang & 41.93 & 117.75 & 844 & Hebei & Mountain \\
9 & Zhangjiakou & 40.78 & 114.88 & 726 & Hebei & Mountain \\
10 & Huailai & 40.40 & 115.50 & 542 & Hebei & Mountain \\
11 & Chengde & 40.97 & 117.93 & 374 & Hebei & Mountain \\
12 & Zunhua & 40.20 & 117.95 & 56 & Hebei & Plain \\
13 & Qinglong & 40.40 & 118.95 & 229 & Hebei & Plain \\
14 & Qinhuangdao & 39.93 & 119.60 & 3 & Hebei & Coastal \\
15 & Baxian & 39.12 & 116.38 & 11 & Hebei & Plain \\
16 & Tangshan & 39.67 & 118.15 & 29 & Hebei & Plain \\
17 & Leting & 39.42 & 118.90 & 12 & Hebei & Coastal \\
18 & Baoding & 38.85 & 115.52 & 19 & Hebei & Plain \\
19 & Raoyang & 38.23 & 115.73 & 20 & Hebei & Plain \\
20 & Huanghua & 38.40 & 117.35 & 3 & Hebei & Coastal \\
21 & Jixian & 37.22 & 115.23 & 23 & Hebei & Plain \\
22 & Tianjin & 39.08 & 117.07 & 4 & Tianjin & Plain \\
23 & Tangguqu & 39.00 & 117.72 & 11 & Tianjin & Coastal \\
\hline & & & & & &
\end{tabular}

Table S2 Trends of surface wind speed (in m s $\mathrm{mec}^{-1}$ ), W925 (in $\mathrm{m} \mathrm{s}^{-1} \mathrm{dec}^{-1}$ ), W850 (in $\mathrm{m} \mathrm{s}^{-1} \mathrm{dec}^{-1}$ ), VSW (in $\mathrm{m} \mathrm{s}^{-1} \mathrm{dec}^{-1}$ ) and DSF (in days dec ${ }^{-1}$ ) and FFE (in thousand metric tons $\mathrm{dec}^{-1}$ ) for different phases 


\begin{tabular}{llll}
\hline & Period & & \\
\cline { 2 - 4 } & $1961-1989$ & $1990-2003$ & $2004-2014$ \\
\hline Surface wind speed & $-0.38^{* *}$ & 0.09 & $-0.29^{* *}$ \\
W925 & $-0.44^{*}$ & 0.30 & 0.10 \\
W850 & $-0.40^{* *}$ & 0.34 & 0.21 \\
VSW & -0.02 & 0.12 & $0.35^{* *}$ \\
DSF & $-0.5^{* *}$ & 0.0 & 0.3 \\
FFE & $18671.4^{* *}$ & $46228.2^{* *}$ & $148581.7^{* *}$ \\
\hline ** and * denotes & statistically & significant changes at $\mathrm{p}<0.01$ and & $\mathrm{p}<0.05$, \\
pectively & & &
\end{tabular}

\section{Supplementary figures}

Figure S1 Anomaly series of Atmospheric Thermodynamic Instability ( ATI) for 1961-2014 in the BTH, ATI $=\left(\mathrm{T}_{850}-\mathrm{T}_{500}\right)-\left[\left(\mathrm{T}_{850}-\mathrm{T}_{\mathrm{d} 850}\right)+\left(\mathrm{T}_{700}-\mathrm{T}_{\mathrm{d} 700}\right)+\left(\mathrm{T}_{500}-\mathrm{T}_{\mathrm{d} 500}\right)\right) ; \mathrm{T}$ and $\mathrm{T}_{\mathrm{d}}$ denote temperature and dew point temperature respectively. The subscript denote 500, 700, and $850 \mathrm{hPa}$. The greater the ATI, the more unstable the stratification.

Figure S2 Variation of annual mean winter temperature difference between 925 and $1000 \mathrm{hPa}$ in the BTH for 1961-2014. A 15-year low-pass Gaussian filter is drawn.

Figure S3. Winter near-surface characteristics of haze and non-haze days for (a) air temperature and (b) relative humidity in the BTH for 1961-2014.

Figure S4. 20-year moving correlation coefficients between winter haze days and relative humidity in the BTH for 1961-2014.

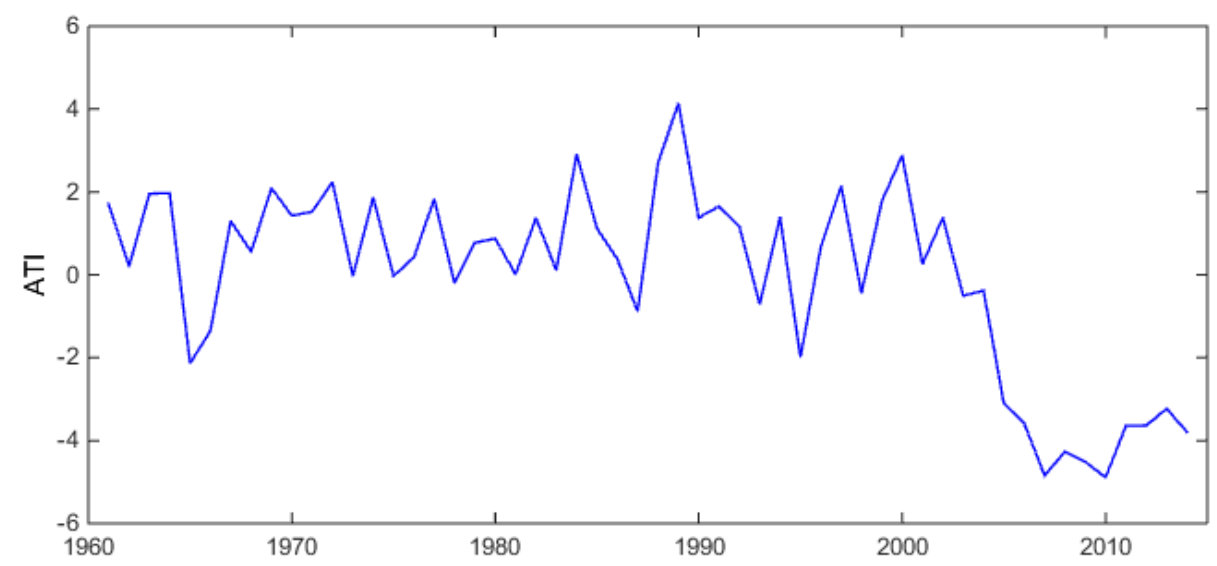

Figure S1 Anomaly series of Atmospheric Thermodynamic Instability ( ATI) for 1961-2014 in the BTH, ATI $=\left(\mathrm{T}_{850}-\mathrm{T}_{500}\right)-\left[\left(\mathrm{T}_{850}-\mathrm{T}_{\mathrm{d} 850}\right)+\left(\mathrm{T}_{700}-\mathrm{T}_{\mathrm{d} 700}\right)+\left(\mathrm{T}_{500}-\mathrm{T}_{\mathrm{d} 500}\right)\right)$; $\mathrm{T}$ 
and $\mathrm{T}_{\mathrm{d}}$ denote air temperature and dew point temperature, respectively. The subscript denote 500, 700, and $850 \mathrm{hPa}$. The greater the ATI, the more unstable the stratification.

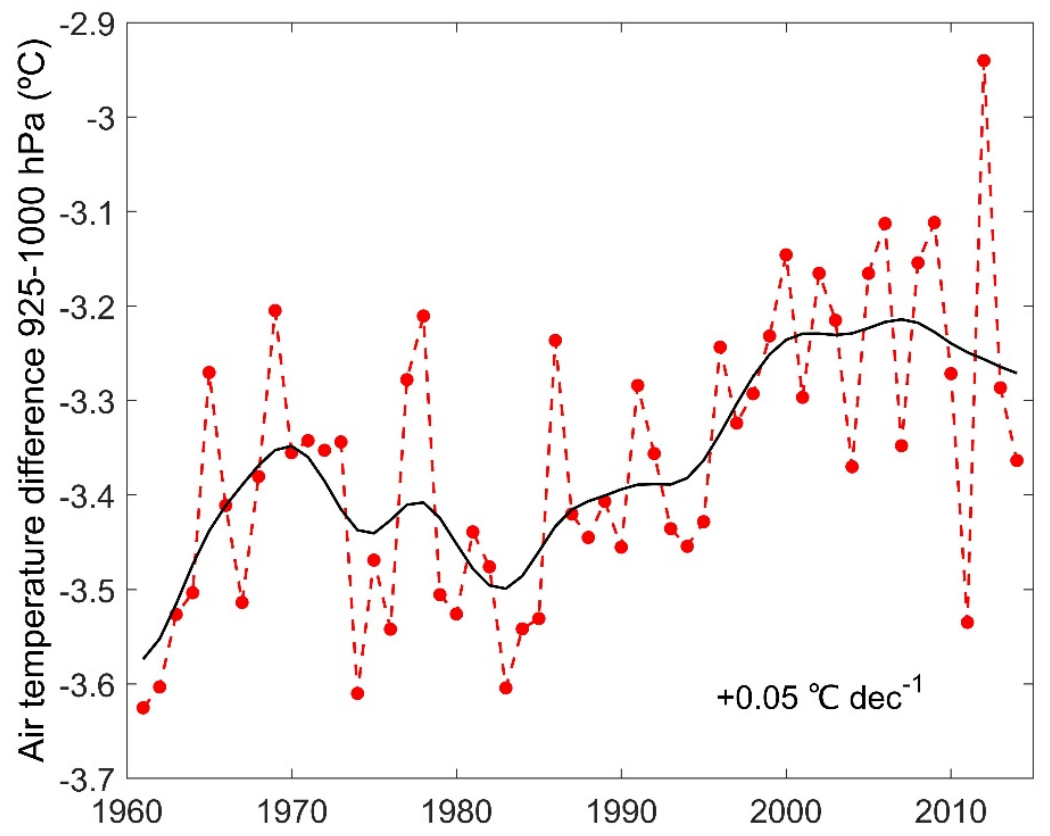

Figure S2 Variation of annual mean winter temperature difference between 925 and $1000 \mathrm{hPa}$ in the BTH for 1961-2014. A 15-year low-pass Gaussian filter is drawn.
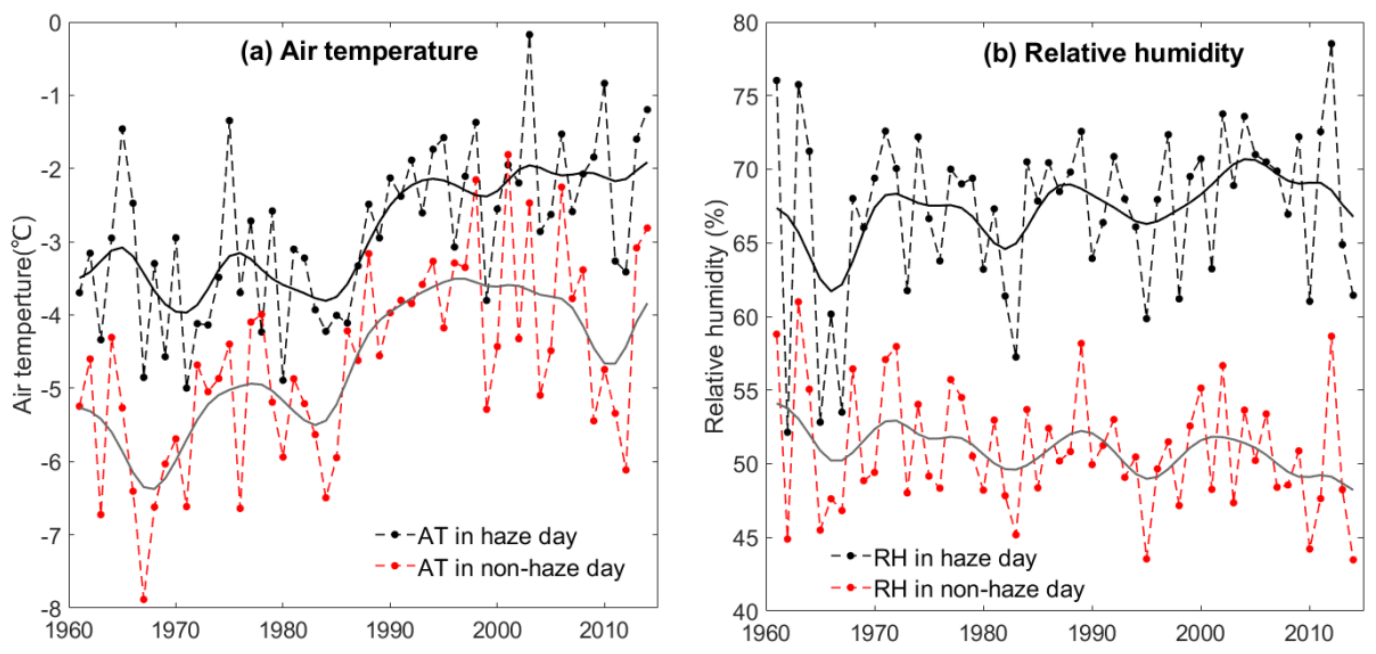

Figure S3. Winter near-surface characteristics of haze and non-haze days for (a) air temperature, and (b) relative humidity in the BTH for 1961-2014. 


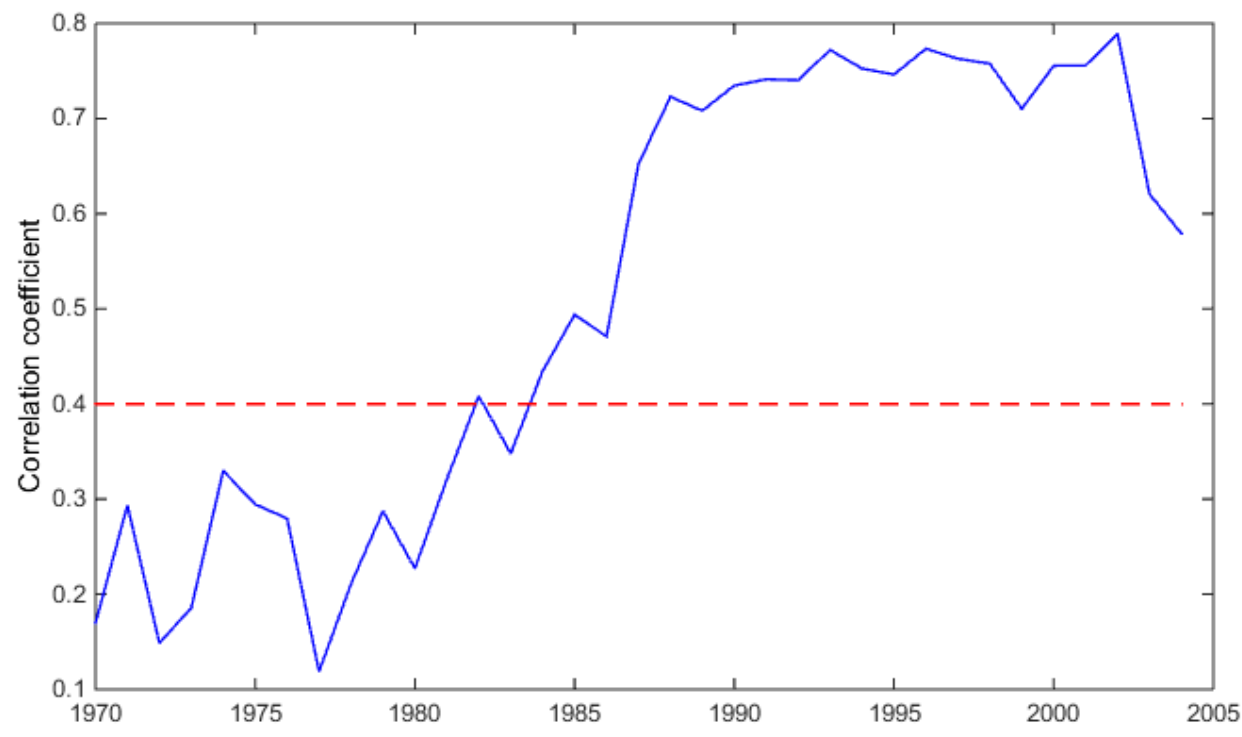

Figure S4. 20-year moving correlation coefficients between winter haze days and relative humidity in the BTH for 1961-2014. 